\title{
Transitioning to High-Performance Homes: Successes and Lessons Learned From Seven Builders
}

SH Widder

AR Kora

MC Baechler
KD Fonorow

DW Jenkins

DJ Stroer

March 2013

Pacific Northwest

NATIONAL LABORATORY

Proudly Operated by Battelle Since 1965 


\title{
DISCLAIMER
}

This report was prepared as an account of work sponsored by an agency of the United States Government. Neither the United States Government nor any agency thereof, nor Battelle Memorial Institute, nor any of their employees, makes any warranty, express or implied, or assumes any legal liability or responsibility for the accuracy, completeness, or usefulness of any information, apparatus, product, or process disclosed, or represents that its use would not infringe privately owned rights. Reference herein to any specific commercial product, process, or service by trade name, trademark, manufacturer, or otherwise does not necessarily constitute or imply its endorsement, recommendation, or favoring by the United States Government or any agency thereof, or Battelle Memorial Institute. The views and opinions of authors expressed herein do not necessarily state or reflect those of the United States Government or any agency thereof.

\author{
PACIFIC NORTHWEST NATIONAL LABORATORY \\ operated by \\ BATTELLE \\ for the \\ UNITED STATES DEPARTMENT OF ENERGY \\ under Contract DE-AC05-76RL01830
}

Printed in the United States of America
Available to DOE and DOE contractors from the Office of Scientific and Technical Information, P.O. Box 62, Oak Ridge, TN 37831-0062; ph: (865) 576-8401 fax: $(865) 576-5728$
email: reports $a$ adonis.osti.gov
Available to the public from the National Technical Information Service 5301 Shawnee Rd., Alexandria, VA 22312 ph: (800) 553-NTIS (6847)

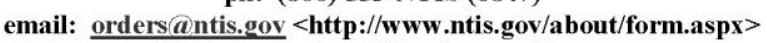 Online ordering: http://www.ntis.gov


PNNL-22375

\title{
Transitioning to High-Performance Homes: Successes and Lessons Learned From Seven Builders
}

\author{
SH Widder ${ }^{1}$ \\ AR Kora ${ }^{1}$ \\ KD Fonorow ${ }^{2}$ \\ MC Baechler ${ }^{1}$ \\ DW Jenkins ${ }^{3}$ \\ DJ Stroer ${ }^{4}$
}

March 2013

Prepared for

the U.S. Department of Energy

under Contract DE-AC05-76RL01830

Pacific Northwest National Laboratory Richland, Washington 99352

\footnotetext{
${ }^{1}$ Pacific Northwest National Laboratory, Richland, WA

${ }^{2}$ Florida Home Energy and Resources Organization (Florida HERO), Newberry, FL

${ }^{3}$ Energy Smart Home Plans, Bonita Springs, FL

${ }^{4}$ Calcs-Plus, Venice, FL
} 



\section{Summary}

As homebuyers are becoming increasingly concerned about rising energy costs and the impact of fossil fuels as a major source of greenhouse gases, the returning new home market is beginning to demand energy-efficient and comfortable high-performance homes. In response, some innovative builders are gaining market share because they are able to market their homes' comfort, better indoor air quality, and aesthetics, in addition to energy efficiency. The success and marketability of these high-performance homes is creating a builder demand for house plans and information about how to design, build, and sell their own low-energy homes.

To help make these and other builders more successful in the transition to high-performance construction techniques, Pacific Northwest National Laboratory (PNNL) partnered with seven interested builders in the hot humid and mixed humid climates to provide technical and design assistance through two building science firms, Florida Home Energy and Resources Organization (FL HERO) and CalcsPlus, and a designer that offers a line of stock plans designed specifically for energy efficiency, called Energy Smart Home Plans (ESHP). A list of participating builders, their locations, the number of homes constructed, and the Home Energy Rating System (HERS) ${ }^{1}$ score of their first high-performance home built as part of the program is provided in Table S.1.

Table S.1. Participating Builders and Location

\begin{tabular}{llcc}
\hline & & & HERS Score of \\
Builder Company & Location & Number of Homes & Frist Home \\
\hline Big Whiskey Builders & Chattanooga, TN & 2 & 77 \\
G.W. Robinson & Gainesville, FL & 4 & 53 \\
Heritage Homes & Wilmington, NC & 7 & 56 \\
Josh Wynne Construction & Sarasota, FL & 1 & 56 \\
Ravenwood Homes & Cape Coral, FL & 1 & 15 with PV/65 \\
& & & without PV \\
Sage Homes, Inc. & Port Charlotte, FL & 1 & 65 \\
Sun Energy Homes & Stuart, FL & 1 & 74 \\
\hline
\end{tabular}

Building America has established goals of developing and demonstrating design solutions that achieve 30\% and 50\% energy savings in comparison to the 2009 International Energy Conservation Code (IECC 2009). The builders in this study built homes that were more efficient than their previous homes, with HERS between 53 and 77. Homes with HERS scores in the 50s exceed the $30 \%$ goal and make headway towards the goal of 50\% energy savings over IECC2009, often on the builder's first attempt at high performance. The experiences of these builders also provide lessons learned that will help other builders meet this goal. Many of the homes also fulfill many of the requirements for DOE Challenge

\footnotetext{
${ }^{1}$ The HERS Index is provided by the Residential Energy Services Network (RESNET) as a uniform and consistent method to test, verify, and communicate a home's level of energy efficiency. The scoring system is based on the asbuilt home characteristics, but assumes default thermostat settings, appliance and hot water usage patterns, and miscellaneous electrical loads (e.g.., TVs, computers) so that a home's rating is not based on a specific homeowner's behavior. http://www.resnet.us/
} 
Home, with the requirements to use a certified HVAC contractor, provide ventilation consistent with the ASHRAE 62.2 Standard ${ }^{1}$, and use low-emission interior finishes proving the most difficult measures for most builders in the study to meet. The experience of this diverse group of builders is helpful in identifying the barriers to broad market adoption of high performance design features.

In partnership with participating builders, ESHP, and local building science firms, PNNL sought to investigate the specific lessons learned and challenges encountered by builders implementing highperformance designs, most for the first time, and document what additional training and resources could be provided to make future efforts more successful for builders and homeowners alike. As indicated in Table S.1, the builders featured in this study cover two climate zones, three states, and span a wide range of experience with high-performance homes, from builders who have been building high-performance homes for over a decade, to builders who have just entered the high-performance market within the last few years. While each builder's experience with high-performance construction methods varies, the project team observed lessons learned common to many of the builders. These lessons learned include design challenges, implementation challenges, and lack of understanding of the Home Energy Rating System (HERS) scoring methodology. In addition, the builders could all benefit from similar resources and information. These lessons learned, identified best practices, and recommended resources are summarized in Table S.2.

Table S.2. Summary of Lessons Learned, Best Practices, and Recommended Resources Identified by Builders Participating in the Transitioning to High-Performance Project

\begin{tabular}{|c|c|c|c|}
\hline $\begin{array}{l}\text { Construction } \\
\text { Phase }\end{array}$ & Lessons Learned & Best Practices & $\begin{array}{l}\text { Recommended } \\
\text { Resources }\end{array}$ \\
\hline Design & $\begin{array}{l}\text { Need to identify high- } \\
\text { performance goals and } \\
\text { construction practices } \\
\text { in the design phase. }\end{array}$ & $\begin{array}{l}\text { Design the home with heating, ventilation, and } \\
\text { air-conditioning design and plumbing layout in } \\
\text { mind from the beginning. }\end{array}$ & - Design Guides \\
\hline Planning & $\begin{array}{l}\text { Need to think through } \\
\text { construction schedule, } \\
\text { note critical points, } \\
\text { and communicate } \\
\text { clearly with } \\
\text { construction } \\
\text { crew/subcontractors. }\end{array}$ & $\begin{array}{l}\text { - Engage tradespeople and construction manager } \\
\text { in a pre-build coordination meeting to ensure all } \\
\text { tradespeople are comfortable with schedule and } \\
\text { expectations are clear. } \\
\text { - Leave time following first midpoint Thermal } \\
\text { Bypass Inspection to address any issues } \\
\text { identified by rater and have rater come back to } \\
\text { inspect modifications. } \\
\text { - Schedule time before installation of attic } \\
\text { insulation to perform "last chance air sealing" } \\
\text { on the attic floor. }\end{array}$ & - Scheduling Guide \\
\hline Implementation & $\begin{array}{l}\text { Need to clearly } \\
\text { articulate roles and } \\
\text { responsibilities and } \\
\text { ensure accountability } \\
\text { of tradespeople. }\end{array}$ & $\begin{array}{l}\text { - Clearly specify expectations and performance } \\
\text { specifications, such as sealing any air barrier } \\
\text { penetrations and verifying proper system } \\
\text { installation through quantified performance } \\
\text { metrics (e.g. building envelope leakage of } 3 \\
\text { ACH50), in contract documents. } \\
\text { - Use clear diagrams, photos, and in-field } \\
\text { demonstrations to help subcontractors }\end{array}$ & $\begin{array}{l}\text { - Building America } \\
\text { Solution Center } \\
\text { (basc.energy.gov) }\end{array}$ \\
\hline
\end{tabular}

${ }^{1}$ ANSI/ASHRAE 62.2-2010, "Ventilation and Acceptable Indoor Air Quality in Low-Rise Residential Buildings" 


\begin{tabular}{|c|c|c|c|}
\hline & & $\begin{array}{l}\text { understand differences in high-performance vs. } \\
\text { typical building practices. } \\
\text { Ensure one person on the job site is responsible } \\
\text { for confirming proper installation and } \\
\text { construction quality. }\end{array}$ & \\
\hline & $\begin{array}{l}\text { Need flexibility and } \\
\text { building science } \\
\text { support to efficiently } \\
\text { optimize construction } \\
\text { process. }\end{array}$ & $\begin{array}{l}\text { Choose foundation and construction types that } \\
\text { are appropriate for site-specific locations and } \\
\text { familiar to local tradespeople and suppliers to } \\
\text { minimize cost and maximize performance and } \\
\text { durability. } \\
\text { Enlist the assistance of an experienced building } \\
\text { scientist to help understand impacts of in-field } \\
\text { design changes, optimize construction process, } \\
\text { and resolve code compliance and certification } \\
\text { issues. }\end{array}$ & $\begin{array}{l}\text { - Design Guides } \\
\text { - HERS point info }\end{array}$ \\
\hline & $\begin{array}{l}\text { Need to educate } \\
\text { homeowners about } \\
\text { true value of high- } \\
\text { performance homes }\end{array}$ & $\begin{array}{l}\text { Discuss all the benefits of high performance, } \\
\text { including total monthly cost of ownership }{ }^{(a)} \text {, } \\
\text { increased comfort, improved indoor air quality, } \\
\text { increased durability, and improved regional } \\
\text { environmental impact with homeowners, } \\
\text { realtors, appraisers, and sales staff. }\end{array}$ & $\begin{array}{l}\text { Resources for } \\
\text { sales people, } \\
\text { homeowners, } \\
\text { appraisers, code } \\
\text { officials }\end{array}$ \\
\hline Certification & $\begin{array}{l}\text { Need information on } \\
\text { relative impact of } \\
\text { design decisions on } \\
\text { HERS rating }\end{array}$ & $\begin{array}{l}\text { - Base design decisions on sound cost- benefit } \\
\text { information to minimize cost while maximizing } \\
\text { performance. }\end{array}$ & - HERS info \\
\hline
\end{tabular}

(a) Total monthly cost of ownership represents the monthly mortgage payment (Principle, interest, tax, and insurance [PITI]) plus energy costs (utility bills).

As a result of this technical assistance, 17 homes will be built featuring climate-appropriate efficient envelopes, ducts in conditioned space, and correctly sized and controlled heating, ventilation, and airconditioning systems. In addition, most builders have communicated to PNNL that they intend to integrate high-performance features into most or all their homes in the future. As these seven builders have demonstrated, affordable, high-performance homes are possible, but require attention to detail and flexibility in design to accommodate specific regional geographic or market-driven constraints that can increase cost. With better information regarding how energy-efficiency trade-offs or design choices affect overall home performance, builders can make informed decisions regarding home design and construction to minimize cost without sacrificing performance and energy savings. 



\section{Acknowledgments}

The authors acknowledge the guidance and support of Eric Werling and Sam Rashkin, and Chris Early of the U.S. Department of Energy Building Technologies Program in sponsoring this work and providing helpful feedback.

The team is most appreciative of the builders who chose to implement high-performance home construction practices and were willing to work with Building America researchers to document and improve their techniques. This work would not have been possible without these motivated individuals and organizations who are passionate about pursuing energy efficiency in the new home market.

The team appreciates the encouragement and guidance from Michael Baechler, Senior Program Manager for this project at PNNL. 



\section{Acronyms and Abbreviations}

$\mathrm{ACH} 50$

BA

BWB

CAD

CFM25

CMU

DOE

$\mathrm{EF}$

EPA

ESHP

FL HERO

gal

HERS

HSPF

HVAC

IECC

PNNL

PV

RESNET

SEER

SHGC air exchanges per hour at 50 pascals depressurization with respect to outside Building America

Big Whiskey Builders

computer-assisted design

cubic feet per minute at 25 pascals depressurization with respect to the interior space

concrete masonry unit

U.S. Department of Energy

Energy Factor

U.S. Environmental Protection Agency

Energy Smart Home Plans

Florida Home Energy and Resources Organization

gallon(s)

Home Energy Rating System

Heating Seasonal Performance Factor

heating, ventilation, and air-conditioning

International Energy and Conservation Code

Pacific Northwest National Laboratory

photovoltaic

Residential Energy Services Network

Seasonal Energy Efficiency Ratio

Solar Heat Gain Coefficient 



\section{Contents}

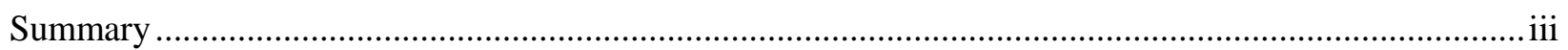

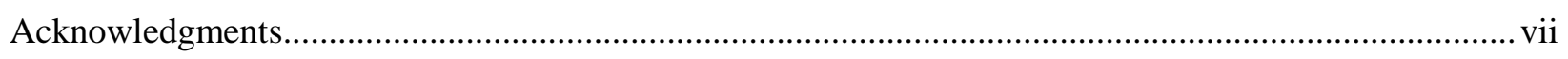

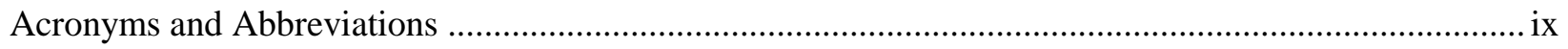

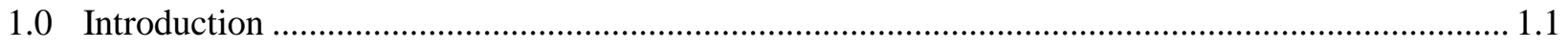

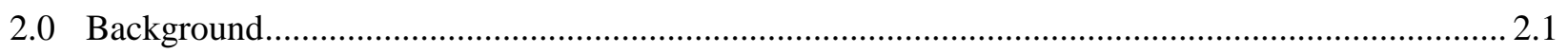

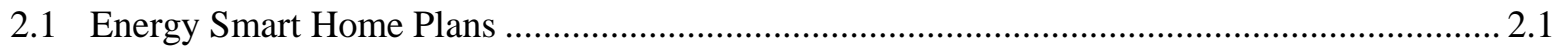

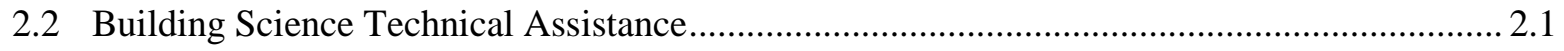

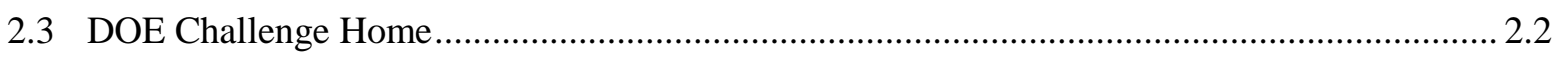

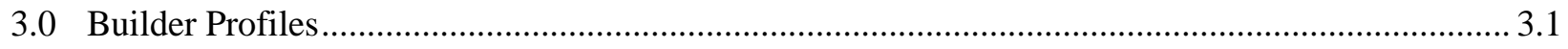

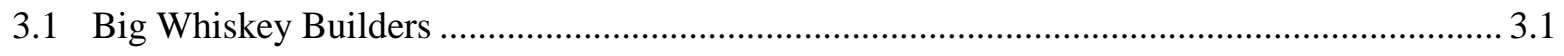

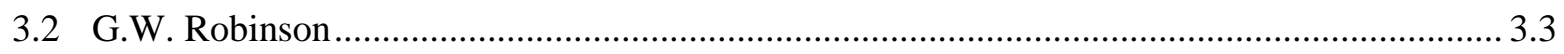

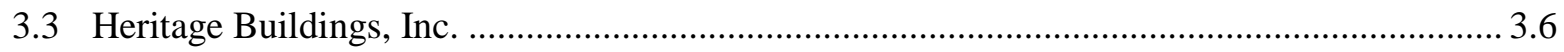

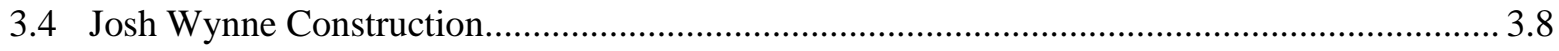

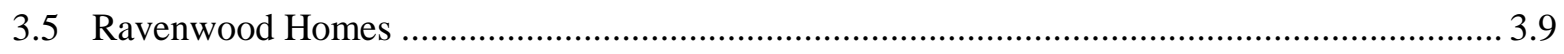

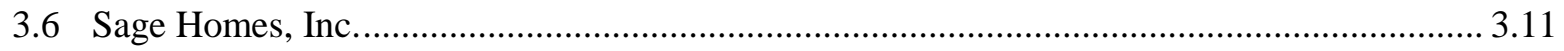

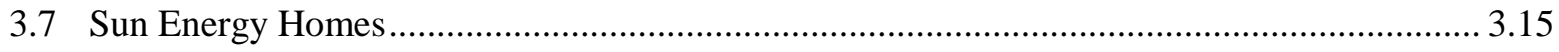

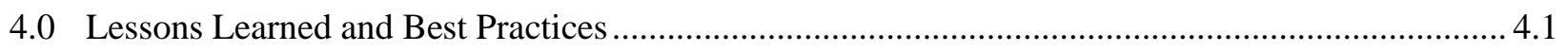

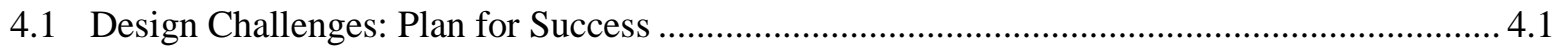

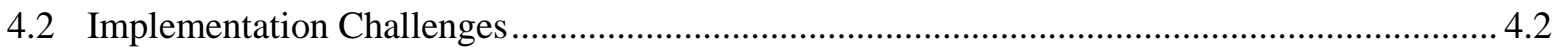

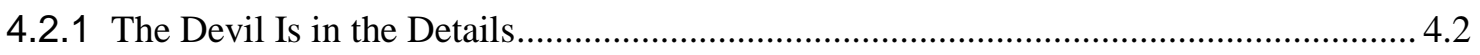

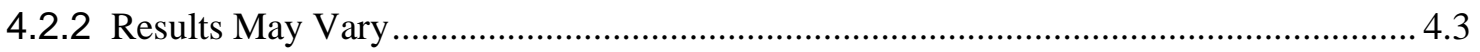

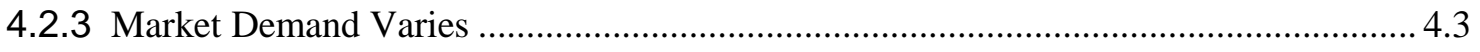

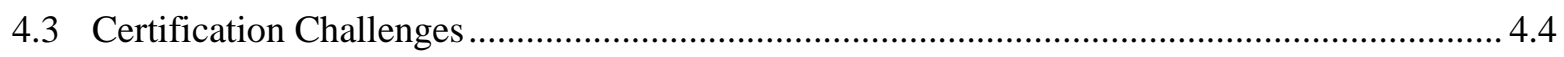

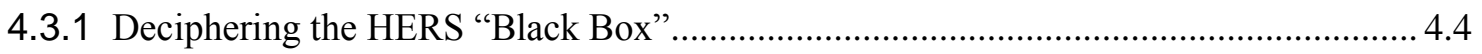

4.3.2 HERS Accuracy for High-Performance Homes......................................................... 4.4

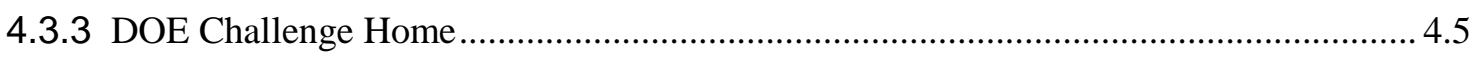

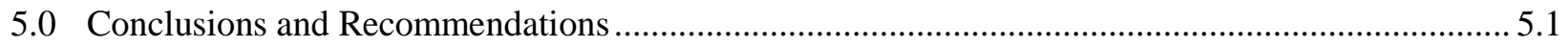

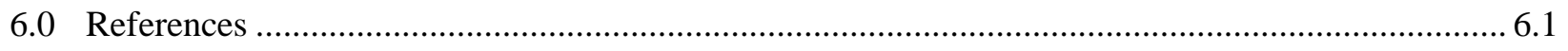

Appendix A Complete List of New Home Builders ...................................................................... A.1

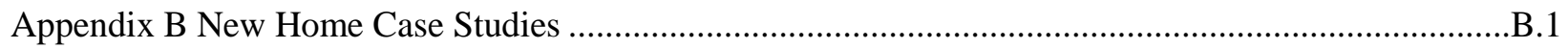

Appendix C Energy Smart Home Plans DOE Challenge Home Plan Set .............................................. 1 


\section{Figures}

$1 \quad$ DOE Challenge Home Logo .......................................................................................... 2.2

2 High-Performance New Home Builders Who Participated in the Study and Stage of

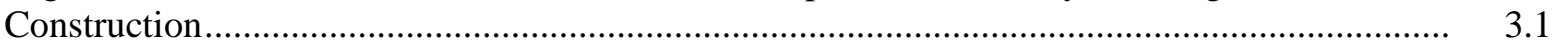

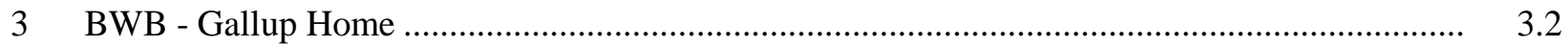

4 G.W. Robinson - First "Generations” Home In Progress.......................................................... 3.4

5 Left: Hole Cut for Small Electrical Wire. Right: Hole Around Soffit Framing. ....................... 3.5

$6 \quad$ Heritage Buildings - Leland Home …................................................................................... 3.6

$7 \quad$ Josh Wynne Construction - Lindroth Home ….................................................................... 3.8

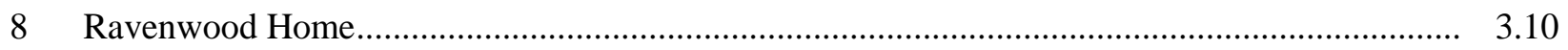

9 HVAC Duct Layout for Sage Homes High-Performance Home ............................................. 3.12

10 Left: Design of Above Ceiling Attic Duct Chases; Right: Implementation of Duct Chase in the Field.

11 Inset Steeled Batt Insulation on Adjacent Walls Between Garage and Living Area as Identified during Thermal Bypass Inspection

12 Estimated Annual Energy Use for the Heritage Home and the Neighboring Home Based on the REMRate Generated HERS Rating, EnergyGauge USA Also Using HERS Defaults, EnergyGauge USA Accounting For Specific Occupancy Factors and Homeowner Behaviors, and Utility Bills.

\section{Tables}

Table S.1. Participating Builders and Location iii

Table S.2. Summary of Lessons Learned, Best Practices, and Recommended Resources Identified by Builders Participating in the Transitioning to High-Performance Project ......................................... iv

Table 1. Gallup Home Characteristics ............................................................................................ 3.2

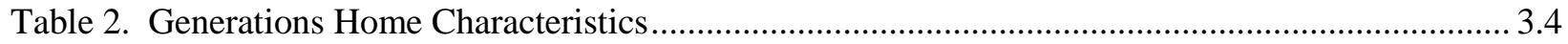

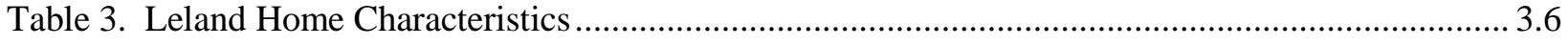

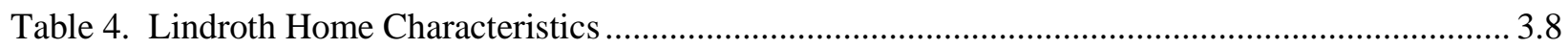

Table 5. Ravenwood Home Characteristics ......................................................................................... 3.10

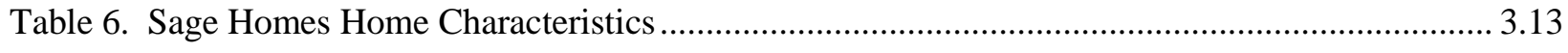

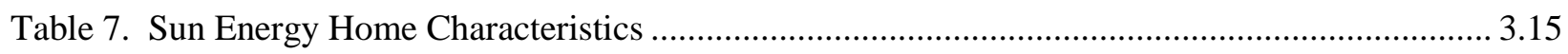




\subsection{Introduction}

Despite the slump in the new construction market, some builders of highly energy-efficient production homes — who are savvy marketers as well — are gaining market share because they are able to position their efficient homes as new products that are very different from other new or existing homes. These builders market their homes' comfort, better indoor air quality, and aesthetics of features like furred-down interior ducts systems that are quite attractive architecturally in addition to achieving low energy bills. As homebuyers are becoming increasingly concerned about rising energy costs and the impact of fossil fuels as a major source of greenhouse gases, the growing new home market is beginning to demand energy-efficient and comfortable high-performance homes (NAHB 2013). The success and marketability of these high-performance homes is creating a demand by other builders for house plans and information about how to design, build, and sell their own low-energy homes.

To help make these and other builders more successful in the transition to high-performance construction techniques, Pacific Northwest National Laboratory (PNNL) partnered with interested builders in the hot humid and mixed humid climates and a designer that offers a line of stock plans designed specifically for energy efficiency, called Energy Smart Home Plans (ESHP; http://www.energysmarthomeplans.com/media). All ESHP designs feature interior duct systems and roof lines that can accommodate a photovoltaic (PV) array, which generates electricity to power the home onsite, large enough to make the home a net zero energy home. Not including any renewable energy systems, these highly energy-efficient homes achieve a Home Energy Rating System (HERS) ${ }^{1}$ score in the 50 to 60 range when properly built. In partnership with participating builders, ESHP, and local building science firms, PNNL sought to investigate the specific challenges and lessons learned encountered by builders implementing high-performance designs, most for the first time, and document what additional training and resources could be provided to make future efforts more successful for builders and homeowners alike.

\subsection{Purpose and Scope}

In 2012 and 2013, the DOE's BA program sponsored research at PNNL to work with new home builders to demonstrate how high-performance homes can deliver lower utility bills, increased comfort, and improved indoor air quality, while maintaining the affordability and marketability of homes. PNNL worked with an energy-efficient home design company, ESHP, and two building science firms, Florida Home Energy and Resources Organization (FL HERO) and Calcs-Plus, to provide technical assistance to seven builders located in hot-humid and mixed-humid climates in their quest to build high-performance homes featuring climate-appropriate efficient envelopes, ducts in conditioned space, and correctly sized and controlled heating, ventilation, and air-conditioning (HVAC) systems. This project addressed an important segment of the building industry, builders who are pursuing high performance homes for the first time. These builders had access to construction documents that are now commercially available, and

\footnotetext{
${ }^{1}$ The HERS Index is provided by the Residential Energy Services Network (RESNET) as a uniform and consistent method to test, verify, and communicate a home's level of energy efficiency. The scoring system is based on the asbuilt home characteristics, but assumes default thermostat settings, appliance and hot water usage patterns, and miscellaneous electrical loads (e.g.., TVs, computers) so that a home's rating is not based on a specific homeowner's behavior. http://www.resnet.us/
} 
to limited assistance from experts in the field. As builders willing to innovate, this self-selected group is certainly no longer in the mainstream of the construction industry. However, any builder willing to take this plunge may face similar problems as those confronted by these builders. In this project, PNNL hoped to catalog the technical and process issues that slowed these builders down, as well as the successes of these builders working from stock plans specifically designed to provide needed details and specifications to reach high-performance standards and with building scientists to understand the key elements of highperformance. As a result of this technical assistance, 17 homes will be built to high performance specs, many of which have reached the goal of a HERS score below 60, and most of the builders intend to integrate high-performance features into all their homes in the future.

\subsection{Report Contents and Organization}

This report summarizes the findings of research on cost-effective high-performance whole-house solutions, focusing on real-world implementation and challenges and identifying effective solutions. The ensuing sections provide project background (Section 2.0), profile each of the builders who participated in the program, and describe their houses' construction characteristics, key challenges the builders encountered during the construction and transaction process); and present primary lessons learned to be applied to future projects (Section 3.0). Overarching themes are identified in the Observations and Lessons Learned section (Section 4.0) and recommendations for future work and improvements are suggested. This report is designed to provide a summary of research results to DOE's Building Technologies Program staff, program managers, and other interested parties to help inform how programs and resources can be aligned to best help make builders across the country successful in transitioning to high-performance construction techniques. Three appendices are also included that provide a full list of new homes builders who were involved with the program (Appendix A), four new case studies that were produced featuring homes or measures of the builders who participated in the program (Appendix B), and a set of ESHP home plans with architectural notes that provide specifications consistent with meeting DOE Challenge Home (Appendix C). 


\subsection{Background}

In 2012, PNNL coordinated with ESHP, FL HERO, and Calcs-Plus to reach out to builders pursuing high-performance construction techniques for the first time. The criteria for selecting builders were that the builder 1) was pursuing a high-performance building technique or whole house design that achieved a target HERS score in the low to mid 50s or less, 2) was trying something for the first time, and 3) had the propensity to carry any knowledge or experience gained forward into many future high-performance homes. As a result of these broad criteria, the experience level and size of builders participating in the program varied greatly, as shown in the Builder Profiles featured in Section 1.0.

\subsection{Energy Smart Home Plans}

Five of the seven builders featured in this project chose to use the ESHP design as a design basis to achieve the high-performance levels required for participation in the project. ESHP is a residential design firms that incorporates significant energy-saving technology into all of its available plans. In addition, ESHP's energy-efficient design features are designed to be built with materials readily available at most builder supply stores, with skills most subcontractors already possess, to minimize additional costs. Some of ESHP efficiency measures include the following:

- HVAC all within the conditioned space, with ducts in dropped soffits below the ceiling plane

- raised heel trusses to accommodate full insulation over the top plate

- 2x6 advanced framing and two-stud California corners to maximize insulation values

- efficient and low solar heat gain windows and deep overhangs to prevent excessive solar heat gain

- roof area large enough to accommodate solar PV array or domestic hot water system to bring the home to net zero energy usage levels.

By using commonly available materials and simple details, ESHP-designed high-performance homes do not have to be considerably more expensive than conventional construction. In addition, ESHP designs recognize that you cannot sacrifice aesthetics, comfort, convenience, or location for the sake of energy efficiency, and that "high performance" encompasses all these elements. However, while highperformance construction may not cost a lot more, it requires an engaged and committed builder, coordination and attention to detail by all the tradespeople, and a good design from the start. Working with builders and building scientists primarily in hot and mixed humid climates, ESHP has made high-performance design and construction accessible for many builders who recognize the value of high-performance homes to their customers, but are not sure how to get started. ESHP is located in Bonita Springs, Florida, and more information is available at http://www.energysmarthomeplans.com/.

"You would not buy a car without researching its MPG; why should your next home be any different?"

Dave Jenkins, Owner Energy Smart Home Plans

\subsection{Building Science Technical Assistance}

As the experiences of the participating builders, described in the subsequent sections, illustrates, constructing successful high-performance homes is dependent on support and assistance from local, 
experienced building scientists and raters who can help builders new to high-performance construction techniques understand the process and key details. In this project, DOE supported participating builders with technical assistance, which was provided by Ken Fonorow of FL HERO and Dennis Stroer of CalcsPlus. Technical assistance consisted of analysis of design options, engineering of the HVAC systems, quality assurance and quality control of the details and system installations, development of scopes of work, field training of the tradespeople, assistance with integrating home energy management and solar domestic hot water and PV systems, documentation, and related activities. Participating builders paid for all rating and certifications associated with these homes. The technical assistance provided by DOE was, in many cases, additional to what would typically be provided by a rater or paid for by a builder, and was much more in-depth than the resources that would typically be sought out by a builder. As the lessons learned in this report demonstrate, engagement of building science at this integral level was key to the success of many of the participating builders and is recommended for any builder considering pursuing high-performance construction for the first time or making a significant design change.

\subsection{DOE Challenge Home}

The DOE Challenge Home is a new home labeling and certification system designed to recognize builders who are building to the highest level in energy efficiency, water efficiency, improved indoor air quality, and renewable energy integration (see Figure 1).
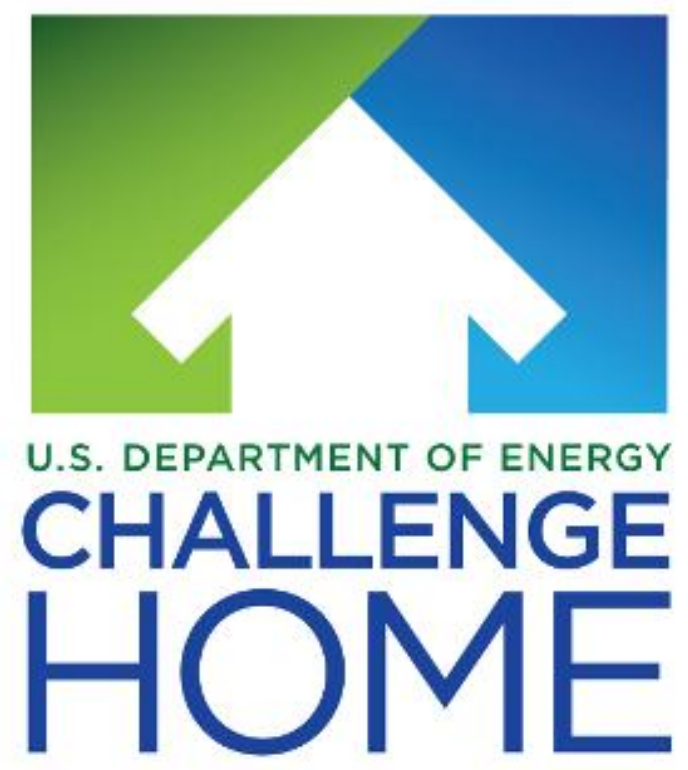

Figure 1. DOE Challenge Home Logo. (Source: DOE 2013)

The program is based on the requirements of the U.S. Environmental Protection Agency's (EPA) Energy Star for Homes Version 3 (Energy Star V3; EPA 2012), along with building science innovations and best practices proven by BA research. In addition to Energy Star V3 requirements, participating homes will do the following: 
- Meet or exceed International Energy and Conservation Code (IECC) 2012 levels of insulation (IECC 2012).

- Install all ductwork in conditioned space.

- Use Energy Star lighting, windows, and appliances.

- Use a centralized hot water distribution system.

- Follow the EPA Indoor airPLUS guidelines (EPA 2013).

The DOE Challenge Home certification allows a prescriptive path and a performance path, both of which result in an average HERS rating for a certified home of around 55 (DOE 2013). As part of this program, participating builders were encouraged, but not required, to certify their homes to the DOE Challenge Home level. However, many ESHP designs are nearly DOE Challenge Home compliant for the hot humid climate already. A set of plans for ESHP's most popular model, Summerville \#109, was modified to include architectural design notes that include all the prescriptive DOE Challenge Home requirements (DOE Challenge Home Plan Set). These files will be used to populate the Building America Solution Center. These plans are attached as Appendix C. However, the home depicted and specified in the DOE Challenge Home Plan Set was prepared after many of the builders had already begun construction. Thus, this specific plan set was not built, in its entirety by any of the participating builders. Similarly, the details of the DOE Challenge Home program were not fully established at the time many of these builders were determining their high-performance goals, which limited the extent to which DOE Challenge Home was pursued by builders who were already trying new construction techniques related to ducts in conditioned space and other high performance features.

For builders interested in participating in the program, registration information and additional resources are available at http://www1.eere.energy.gov/buildings/residential/ch_index.html. 



\subsection{Builder Profiles}

Fourteen builders were initially engaged in this study (refer to Appendix A for a full list of builders). Seven builders that moved forward with building high-performance homes are indicated in Figure 2, along with the number of homes and the construction progress. The other seven builders that did not elect to move forward with constructing high-performance homes at this time are also indicated with red triangles, but their company names are not listed.

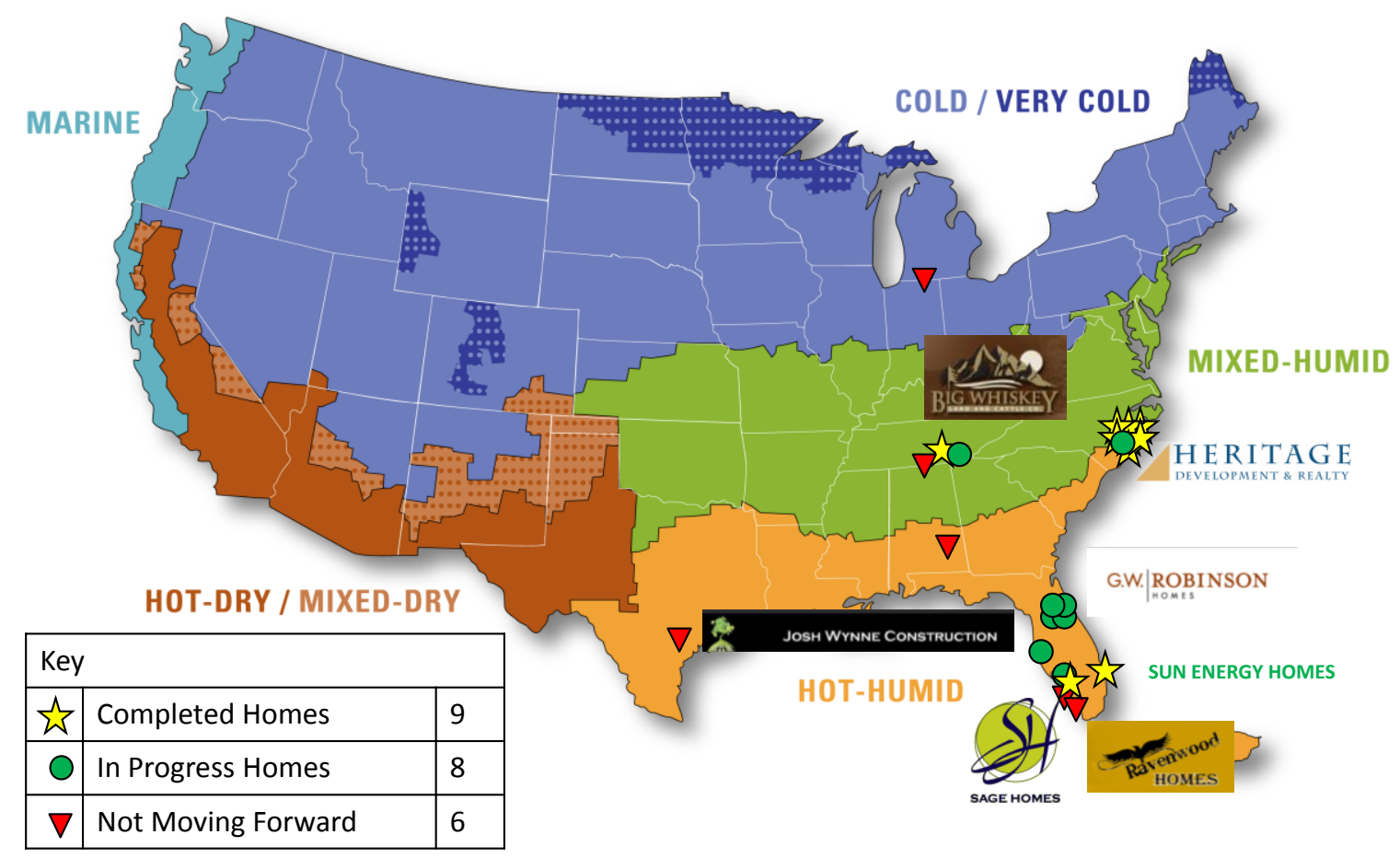

Figure 2. High-Performance New Home Builders Who Participated in the Study and Stage of Construction. Builders that did not move forward with constructing high-performance homes at this time are also indicated with red triangles, but their company names are not listed.

The following sections contain builder profiles for each of the seven builders who constructed highperformance homes, most of which were based on the ESHP designs. Each profile introduces the builder, describes the home characteristics for each of their high-performance homes completed as part of this study, summarizes the primary challenges the builders encountered implementing these high-performance designs, and lists key lessons learned throughout the process. Each section concludes with a statement regarding the builder's overall experience with building and selling high-performance homes and whether the builder will continue to offer and build high-performance homes in the future.

\subsection{Big Whiskey Builders}

Big Whiskey Builders (BWB) is located in Chattanooga, Tennessee. Owned by Rick Harris, the company builds approximately 15 to 20 homes per year. An early adopter of high-performance building in this area, BWB's affinity for new technology was one reason for its initial efforts to incorporate 
energy-efficient features such as radiant roofs, tankless water heaters, and high efficiency air conditioning into its homes. Learning about ESHP homes introduced BWB to the importance of investing in building envelope and integrated home design to achieve higher performance homes and as a result, the company has moved toward using ducts in conditioned space and advanced framing techniques.

BWB's first high-performance home, named Gallup, is a modified ESHP Summerville model that includes a second floor (by customer request). This 2,222- $\mathrm{ft}^{2}$ home features slab flooring, ducts in conditioned space, and a high-performance heat pump. After the design was completed but before construction began, the home was moved to a different neighborhood because the original lot was no longer available. As a result, BWB modified the original design to fit the constraints of the new lot. The home was completed on February 15, 2013. Figure 3 is a photo of the home. Table 1 summarizes the home's characteristics.

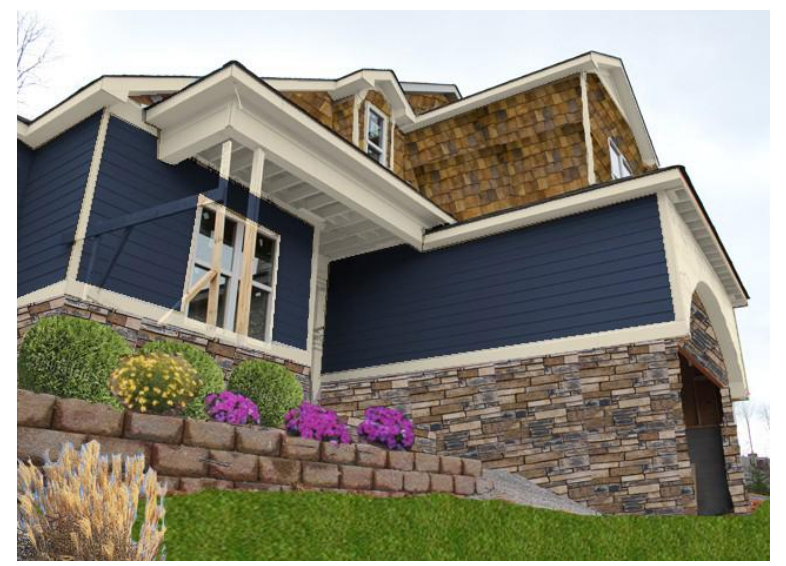

Figure 3. BWB - Gallup Home
Table 1. Gallup Home Characteristics

\begin{tabular}{lc}
\hline \multicolumn{1}{c}{ Characteristic } & Gallup Home \\
\hline HERS Rating (Final) & 77 \\
Size $\left(\mathrm{ft}^{2}\right.$ ) & 2,357 \\
Climate Zone & Mixed-Humid \\
Building Leakage (ACH50) & 5.5 \\
Duct Leakage (CFM25 out) & 97 \\
Heat Pump & 15 SEER/8.5 HSPF \\
Water Heater & Electric 50 gal 0.9 EF \\
Attic Insulation & R-38 Blown \\
Wall Insulation & R-22, 2x4 framing \\
Ventilation & None \\
Windows & $\mathrm{U}=0.32 / \mathrm{SHGC}=0.29$ \\
\hline
\end{tabular}

BWB experienced some challenges while building the Gallup home, including the following:

- Regional construction market constraints. High-performance home construction is not as common in this area as it is in other parts of the country, which contributes to higher material costs for some items. For example, spray foam insulation was considered given the customer request for a second story. However, the quoted cost for spray foam insulation was five times the cost to insulate any other BWB homes; therefore, spray foam insulation was not cost-effective. Engineered trusses were also considered, but were quoted at a cost that was 1.5 times the cost for stick framing, so they were also determined to not be cost-effective. According to BWB, there are no local manufacturers of engineered trusses, and local contractors have limited experience with the approach, which results in higher costs. Unlike other parts of the country (e.g., Florida), engineered trusses are not common, which is likely another reason for the higher costs. BWB did implement a stick-built raised heel, but it was not accepted by the code official.

- Geographical constraints. Building the home with a concrete slab resulted in more site preparation work to remove topsoil and add compacted clay, resulting in higher-than-expected costs for foundation work. Relocating the home lot after the initial designs were completed also contributed to additional design changes and additional cost. 
- Limited HERS experience. BWB's limited knowledge of how individual components (e.g., lighting, window performance) affect the overall HERS score may have been one reason for the lower-than-expected HERS scores. A better understanding of how design elements affect the HERS score would help BWB make better informed decisions when considering the costs and benefits of various design elements. In addition, HERS raters or other building science technical support are not readily available in BWB's local area, meaning BWB does not have quick access to resources for information on performance trade-offs.

BWB gained valuable experience and lessons learned during the design and construction process, including the following:

- High-performance homes require advanced planning. More precise pre-planning and layout design is required for high-performance strategies such as slab flooring and ducts in conditioned space. BWB struggled with the new schedule required to hang ducts in framed soffits before sheetrock is installed. For example, it was only after the interior duct runs were completed that BWB identified a more effective approach that could have been used. Similarly, slab flooring also requires more precise plumbing layout because the lines cannot be modified after the floor is laid. Slab flooring also requires more coordination with contractors, including an additional visit from the plumber to complete the installation.

- Flexibility required to adapt to site-specific constraints. Site conditions in Chattanooga may not be ideal for slab flooring. More varied topography than in other parts of the country, soil characteristics, and a tendency for standing water requires more site preparation to prepare for the raised concrete slab. Thus, a crawlspace may be more appropriate for homes in BWB's geographical location. With better information regarding the energy efficiency and HERS rating impacts of specific design decisions, BWB can achieve greater flexibility in its high-performance home designs, reducing cost without sacrificing performance.

Despite the challenges BWB experienced when building its first ESHP-designed home, BWB wants to continue building high-performance homes and learning more about the HERS rating system. By gaining a better understanding of the HERS rating system, BWB will be better equipped to make better informed design decisions quickly, resulting in better home performance and lower costs.

"I believe in high performance building; there are results that show it works. I will pursue high performance building again, and am committed to building ESHP designs to spec."

Rick Harris, Owner Big Whiskey Builders

\subsection{G.W. Robinson}

G.W. Robinson, located in Gainesville, Florida, was founded in 1968 and has been building energyefficient homes since 2001 when it first began working with DOE to build homes to BA's Builders Challenge requirements; it was recognized by DOE in 2007 for its efforts as a leader and pioneer of highperformance building in Florida. In 2012, G.W. Robinson began pursuing ESHP designs after seeing the successful results experienced by other local builders (e.g., Tommy Williams Homes, see PNNL 2011 and 2012). Recognizing the difficulty of incorporating new energy-efficiency features such as ducts in conditioned space into existing home plans, G.W. Robinson took the opportunity to incorporate ducts in conditioned space into a new series of plans it is introducing, called "Generations," that will include 30 unique house plans all based on three modified ESHP designs and one custom design. G.W. Robinson is 
initially building four "Generation" homes. Construction began on two of these four homes in early 2013, targeting mid-April for completion so the homes could be included in the Alachua County Parade of Homes in April 2013. The homes are on track to be completed on schedule, and a contract has been secured for the new, custom design home.

The homes currently under construction are 1,619 $\mathrm{ft}^{2}$ and 2,150 $\mathrm{ft}^{2}$, and feature ducts in conditioned space, tankless water heaters, and high-performance heat pumps. Figure 4 shows the $1,619-\mathrm{ft}^{2}$ home near the end of construction in March 2013, and Table 2 summarizes the home's characteristics.

Table 2. Generations Home Characteristics

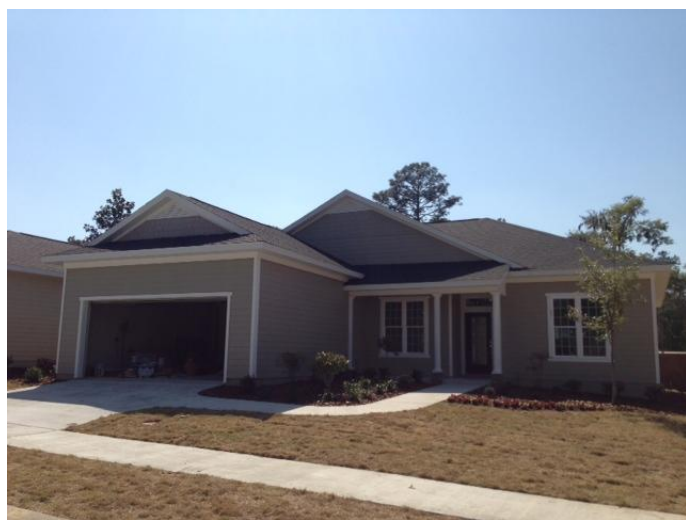

Figure 4. G.W. Robinson - First "Generations" Home In Progress

\begin{tabular}{lc}
\hline \multicolumn{1}{c}{ Characteristic } & Home \\
\hline HERS Rating (Initial) & 53 \\
Size $\left(\mathrm{ft}^{2}\right.$ ) & 1,619 \\
Climate Zone & Hot-Humid \\
Building Leakage (ACH50) & $3.5^{(\mathrm{a})}$ \\
Duct Leakage (CFM25 out) & $49^{(\mathrm{a})}$ \\
Heat Pump & 16 SEER/9 HSPF \\
Water Heater & Tankless natural gas (0.83 EF) \\
Attic Insulation & R-38 \\
Wall Insulation & R-19 \\
Ventilation & Run-time vent \\
Windows & $\mathrm{U}=0.35 /$ SHGC $=0.30$
\end{tabular}

(a) Estimated; home has not yet undergone final air leakage testing.

Challenges that G.W. Robinson experienced while building these homes included the following:

- Attention to detail when installing soffit framing and electrical wiring. In all cases, duct soffits were very well constructed and duct connections were tight and properly sealed. However, when constructing ducts below the ceiling plane, the primary objective is to achieve a well-sealed air barrier at the ceiling plane formed by the ceiling drywall. In this home, larger than necessary holes were cut into the drywall to accommodate the soffit framing and electrical wires, as shown in Figure 5.

Fortunately, this issue was identified midway through construction and could still be easily corrected by walking the attic floor prior to insulation installation and sealing any identified holes with foam or caulk. A blower door is a great tool to use to identify holes and perform targeted sealing before the attic insulation makes those areas less accessible.

The performance impact of installing ducts in conditioned space is not clear. While G.W. Robinson believes in the concept of ducts in conditioned space, company owner and president Gay Robinson is not convinced they will result in substantial energy savings on top of their already efficient designs. G.W. Robinson typically builds homes with HERS scores of less than 60 and modeling only predicted a HERS score 1 or 2 points lower when ducts in conditioned space were included. However, G.W. Robinson is convinced that building ducts in planned, dedicated, and protected soffits results in a more durable and long-term design and a better product for its customers. These additional values make the ducts in conditioned space make sense for Gay and her company, not necessarily just the energy or cost impacts. 

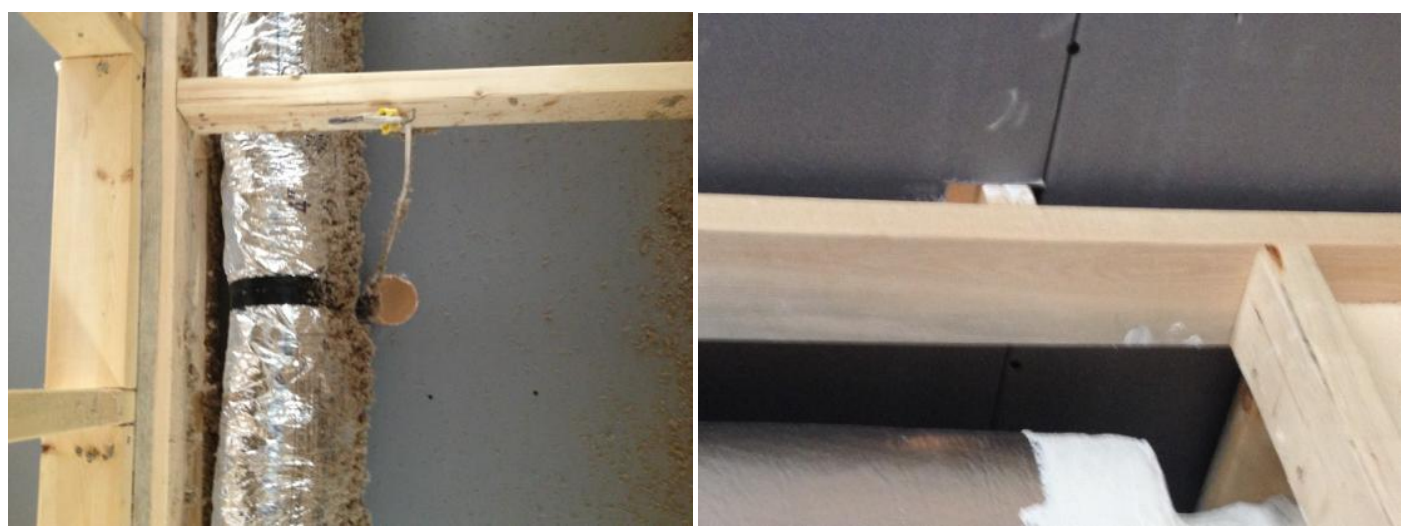

Figure 5. Left: Hole Cut for Small Electrical Wire. Right: Hole Around Soffit Framing.

G.W. Robinson's experience with constructing these high-performance homes led to many lessons learned, including the following:

- Ducts in conditioned space must be part of the design. G.W. Robinson has considered ducts in conditioned space previously, but determined it was too costly to consider if its existing plans needed to be modified. G.W. Robinson's introduction of a new line of home plans, called its "Generation" series, presented an ideal opportunity to design the homes to accommodate ducts below the ceiling plane in the new designs.

- Effective training and communication with tradespeople is crucial to achieving success. A longtime builder in Gainesville, G.W. Robinson has long-standing and cooperative relationships with its subcontractors. G.W. Robinson also engaged and met with all the subcontractors prior to construction to explain the construction schedule so everyone was on the same page, knew what was expected of them, and knew what was coming. That way, even subcontractors who weren't familiar with specific high-performance features could anticipate what was coming. Because of the relationships that G.W. Robinson has built and maintained over the years and the best practice of meeting as a team to review schedules, roles, and responsibilities, the company was able to build its first home with ducts in conditioned space with little to no difficulties. "We made some changes," noted Gay Robinson, "and it required more trips [for some of the subcontractors]. It wasn't perfect, but we didn't have to take anything out... and people were ready for it." G.W. Robinson also follows up with a meeting involving all the subcontractors and tradespeople after construction is completed to review how the job went and identify areas for improvement. This should ensure G.W. Robinson's next home construction goes even more smoothly.

G.W. Robinson's positive experience with highperformance homes and ducts in conditioned space is made clear by their plans to continue using ESHP designs in its "Generations" series. G.W. Robinson also plans to modify some of its Classic designs to bring the ducts into conditioned space as well, although the proven performance information in occupied homes is what will really convince owner Gay Robinson of the long-term value of ducts in the conditioned space.

"We are doing [ducts in conditioned space] because it makes sense for the longevity of the system, not just for energy or cost."

Gay Robinson, President G.W. Robinson Homes 


\subsection{Heritage Buildings, Inc.}

Heritage Buildings, Inc., located in North Carolina, has been building homes for more than 15 years, building about 20 homes per year. Heritage Buildings owner, Vic Sikka, has been interested in highperformance homes for some time and was interested to find ESHP's "net-zero ready" plans through an on-line stock plan publisher (Architectural Designs) and try an ESHP design. Heritage Buildings' first high-performance home, Leland, was designed and built in 2011 and achieved a final HERS rating of 56. The home's actual performance has been $40 \%$ lower than the HERS rating predicted, using just 8,075 $\mathrm{kWh}$ annually as opposed to the HERS-predicted 12,280 $\mathrm{kWh}^{1}$. Vic's second home built using an ESHP design was constructed with similar characteristics as his first, but obtained a HERS score of 63 despite using additional energy-efficiency features in this home. Due to this inconsistency, as well as the perceived ambiguity regarding how specific home characteristics or energy-efficiency measures affect the homes HERS rating, Vic is disinclined to rely on HERS ratings to evaluate or market his homes. Vic has observed that Heritage homes consistently use less energy than their HERS score would predict, and believes that a home's utility bills are a more straightforward and reliable way to communicate performance.

Figure 6 is a photo of the completed Leland home, and Table 3 summarizes the home's characteristics. This home was also featured in a BA case study published in October 2012 (Appendix B).

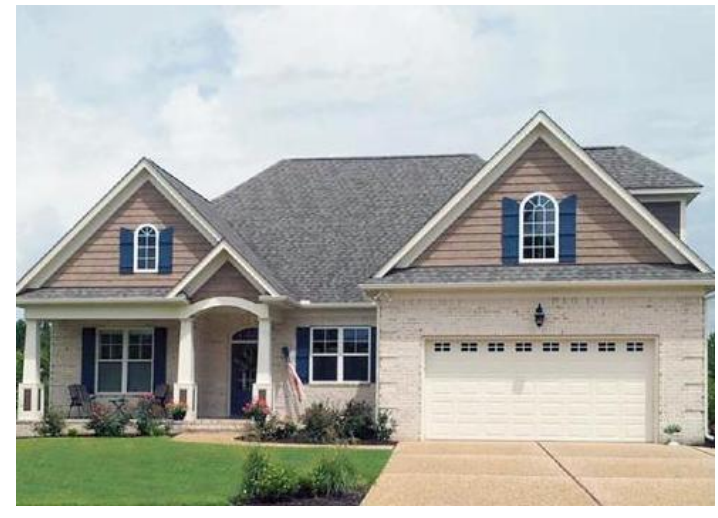

Figure 6. Heritage Buildings - Leland Home

Table 3. Leland Home Characteristics

\begin{tabular}{lc}
\hline \multicolumn{1}{c}{ Characteristic } & Leland Home \\
\hline HERS Rating (final) & 56 \\
Size $\left(\mathrm{ft}^{2}\right.$ ) & 2,396 \\
Climate Zone & Hot-Humid \\
Building Leakage (ACH50) & 3.41 \\
Duct Leakage (CFM25 out) & 46 \\
Heat Pump & 16 SEER/9 HSPF \\
Water Heater & Tankless propane (0.82 EF) \\
Attic Insulation & R-38 w/ radiant barrier \\
Wall Insulation & R-15 \\
Ventilation & Balanced \\
Windows & $\mathrm{U}=0.32 /$ SHGC $=0.33$
\end{tabular}

Challenges that Heritage has experienced when building high-performance homes include the following:

- Subontractor experience and interest in high-performance building. Contractors in North Carolina may not have experience building high-performance homes, so builders need to be actively involved in training and educating contractors on proper installation. Heritage found that for some of its subcontractors, direct guidance on multiple projects was required before the contractor was able to fully adopt the new processes. In addition, to ensure success, Vic personally took responsibility "to

\footnotetext{
${ }^{1}$ This home also has a propane tankless water heater. Because precise propane consumption information was not available, only the electricity usage of the home was compared to the predicted electricity usage based on the HERS rating.
} 
walk through every home under construction with a can of spray foam and caulk, plugging every hole I find."

- Emerging market. While some of Heritage Buildings' customers are very interested in highperformance building (its first ESHP-designed home was initiated by customer request), Heritage believes that the majority of its current customer base is hesitant to invest in a truly high-performance home. However, Heritage will continue to offer the high-performance package, for an incremental cost of \$7,500 and believes that a changing demographic will translate into more customers attracted to the lifetime cost savings and other benefits of a high-performance home, and not be deterred by increased capital costs. Heritage now employs two individuals who have been trained specifically to explain and market high-performance features to potential homebuyers.

- Less net cost savings from reduced HVAC system size. Heritage has found that while smaller HVAC systems in high-performance homes compared to standard homes have lower capital costs, labor costs to correctly design and install the systems are often higher because measures such as additional pre-planning for duct runs and proper duct installation and sealing are required. As a result, Heritage has not experienced the same overall savings that other builders have reported from reducing HVAC system size.

Heritage Buildings' experiences with high-performance building have resulted in many lessons learned, including the following:

- Utility bills and customer satisfaction are the true measures of performance. Heritage has found that homeowners in their high-performance homes, built with ESHP designs, are consistently performing below their measured HERS values. Because of this, Vic believes that real-life utility bills are the best indicator of a home's energy performance. This belief also resonates with homeowners. Vic claims that every time he speaks to a homeowner who lives in a high-performance Heritage home, the homeowner cannot end the conversation without mentioning the homes' low utility bills. The satisfied homeowners in Heritage's high-performance homes are now the best sales force this builder has to help differentiate his product in the market.

- Attention to details is key to any high-performance effort. While Heritage was successful with high-performance construction from the beginning and did not find the measures overly burdensome or difficult, VIc noted that the builder must be a willing and able participant to make the home a success. Measures such as careful sealing of any electrical and plumbing holes are necessary to help homeowners realize the full energy-savings potential of a high-performance home. These are not difficult measures, but they require the builder to take responsibility for the workmanship and attention to detail from all the tradespeople.

Heritage Buildings has continued building high-performance homes, with two more homes nearing completion as of March 2013 for a total of seven constructed ESHP-designed homes. Given the positive customer feedback and current market drivers, Vic expects that high-performance homes will continue to be a focus for the company. In addition, after having built several

"The builder's commitment to improving their product is seen in the results they achieve."

Vic Sikka, Owner Heritage Buildings, Inc. ESHP-designed homes, Vic is even more committed to highperformance construction practices, including ducts in conditioned space, raised heel trusses to accommodate full-depth insulation over the top plates, advanced framing, Energy Star windows, and 
detailed air sealing to prevent thermal bypasses. "The best question," says Vic, "is to ask a builder: if you built a house, what would you build? If I were building a house for me and my family, this is what I would build" - referring to the high-performance features in ESHP-designed homes.

\subsection{Josh Wynne Construction}

Josh Wynne Construction, located in Sarasota, Florida, has been in operation since 1999 and currently employs four staff. It builds about four high-end homes per year, and has focused on high-performance, energy-efficient homes since the business' inception. As a result, the company has become known for building homes that have net zero or near net zero energy use.

The home included in this study is a $2,178-\mathrm{ft}^{2}$ home featuring concrete masonry unit (CMU) walls and a sealed attic with spray polyurethane foam meaning the ducts are placed in conditioned space. This home was included in the study because load calculations were done for both spray foam and cellulose insulation types to determine the impact on the HERS rating. Also, Josh's homes are a true model of high-performance home design: maximum energy conservation, maximum water conservation, complete indoor health considerations, maximum durability, and regional environmental stewardship. The homeowners have committed to selecting Energy Star appliances, although the specific appliances have not yet been selected. Achieving net zero energy use is a primary goal for the homeowner and builder; PV panels will be used to generate electricity onsite. Figure 7 is a photo of the partially completed home. Table 4 summarizes the home characteristics. Notably, this home will be certified to Energy Star, Leadership in Energy and Environmental Design, Florida Green Building Coalition, and DOE Challenge Home certification systems.

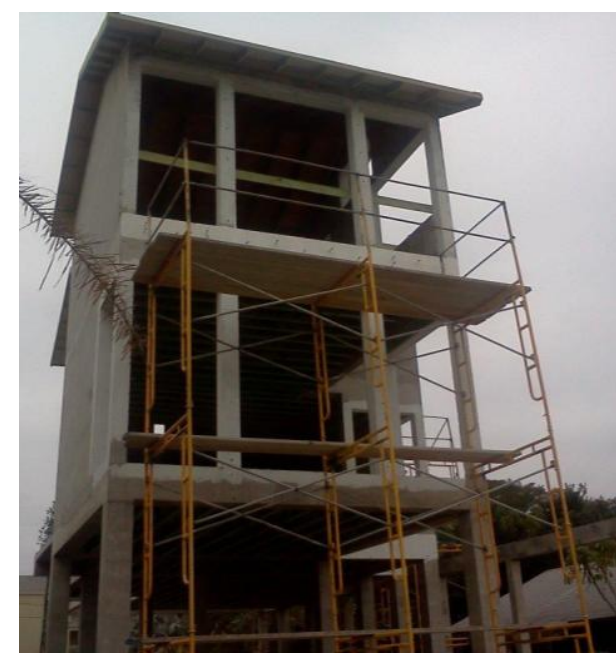

Figure 7. Josh Wynne Construction Lindroth Home
Table 4. Lindroth Home Characteristics

\begin{tabular}{lc}
\hline \multicolumn{1}{c}{ Characteristic } & Longboat Home \\
\hline HERS Rating (Initial) & 56 \\
Size $\left(\mathrm{ft}^{2}\right.$ ) & 2,178 \\
Climate Zone & Hot-Humid \\
Building Leakage (ACH50) & Not yet completed \\
Duct Leakage (CFM25 out) & Not yet completed \\
Heat Pump(s) & 16.5 SEER/9 HSPF \\
& 14.5 SEER/8.2 HSPF; \\
& both with zonal dampers and \\
Water Heater & controls \\
Attic Insulation & Tankless natural gas \\
Wall Insulation & R-21 spray foam \\
& CMU filled with R-5 foam \\
Ventilation & insulation; interior R-7.1 board \\
Windows & 75 cfm supply \\
PV Array & $\mathrm{U}=0.31 / \mathrm{SHGC}=0.22$ \\
\hline
\end{tabular}

Josh Wynne's experience with high-performance building has resulted in many lessons learned, including the following:

- Attention to detail is also required for successful sealed attics. Spray foam in attics must be complete and continuous to be effective. This is especially important in humid climates where high 
dew point conditions can result in condensation on the duct system. In addition, the indirectly and directly conditioned spaces must be connected to prevent pressure imbalances. Using recessed lights can create this connection, because these lights typically result in air transfer between the living spaces and the attic.

\section{- Lower spray foam R-values may result in equivalent performance with higher loose fill} insulation R-values. There is belief in the field and claims from the industry that R-19 spray foam insulation performs as well as R-30 loose fill insulation due to installation issues that affect the overall installed R-value of loose fill or batt insulation. While these claims are currently unsubstantiated by data, preliminary HERS modeling on this home using EnergyGauge USA ${ }^{1}$ energy modeling software indicated that R-30 insulation in the attic reduced the HERS score by 2 points (56 to 54) and reduced the HVAC size from 2.34 tons to 2.27 tons. This small impact points to the need for field data to substantiate the claims of better installed performance from spray foam insulation. One hypothetical cause for this claim could be the more consistent and homogeneous application of spray foam compared to loose fill and batt insulations, which can suffer from inconsistent application, reducing their installed $\mathrm{R}$-value in the field.

- Homes consistently outperform HERS rating goals. As a form of warranty to Josh Wynne's homebuyers, Josh will pay for the first 3 months of utility bills for any home he builds. By doing this, Josh has noticed that the homes are consistently performing better than their HERS scores would predict. This may be a result of inherently conservative homeowners being more likely to purchase Josh's efficient homes (a "conservation bias"), or it could be related to the fact that comfortable wellbuilt homes allow and encourage homeowners to exhibit more energy-efficient behavior. For example, if the home has sufficient moisture control and reasonable relative humidity levels, homeowners may not need to turn down the thermostat as much to maintain comfort in Florida's hot humid climate.

Josh has always been committed to high-performance homes and will continue to dedicate his company to building exceptionally well-built and resource efficient homes. Josh will even encourage homeowners to consider smaller homes, because he doesn't like to build anything larger than about $4,000 \mathrm{ft}^{2}$, and believes customer education is a key part of the high-performance construction process.

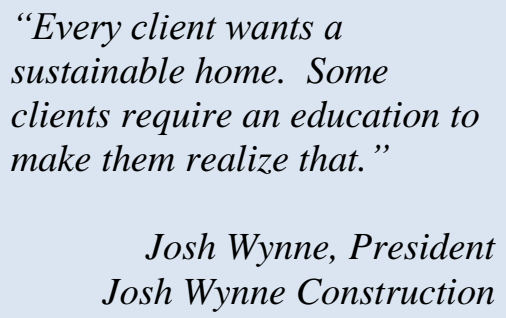
sustainable home. Some clients require an education to make them realize that."

Josh Wynne, President Josh Wynne Construction

\subsection{Ravenwood Homes}

Ravenwood Homes, located in Southwest Florida, has been constructing homes for about 10 years and builds approximately 10 to 20 homes per year. Ravenwood was attracted to the successful net zero energy homes that other builders in the area had constructed, and in 2011 chose to use the ESHP Solara Model home as the base design for its first attempt at a net zero energy home.

High-performance features in the home include a vented roof with R-38 insulation, Seasonal Energy Efficiency Ratio (SEER) 16 air conditioning (the home is located in a cooling-dominate climate), and

\footnotetext{
${ }^{1}$ EnergyGauge USA is a detailed, hourly energy simulation tool developed and supported by the Florida Solar Energy Center. http://www.energygauge.com/usares/
} 
ducts in conditioned space. This was the first home in which Ravenwood used dropped soffits to install ducts in conditioned space and provided an opportunity for the builder and tradespeople to learn best practice insulation installation techniques. Renewable energy is generated by a 120-gallon solar hot water system, and a 26-panel, 5.98-kW PV array. Figure 8 shows the completed home, and Table 5 summarizes the home's characteristics.

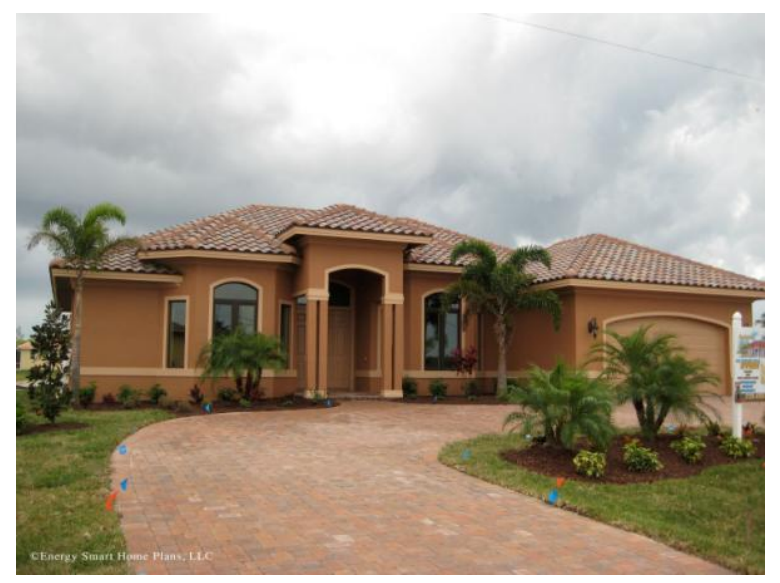

Figure 8. Ravenwood Home
Table 5. Ravenwood Home Characteristics

\begin{tabular}{lc}
\hline \multicolumn{1}{c}{ Characteristic } & Home \\
\hline HERS Rating (final) & 15 with PV/65 without PV \\
Size (ft ${ }^{2}$ ) & 2,248 \\
Climate Zone & Hot-Humid \\
Building Leakage (ACH50) & 4.39 \\
Duct Leakage (CFM25 out) & 69.5 \\
Heat Pump & SEER 16, Electric Heat \\
Water Heater & 120 gal solar \\
Attic Insulation & R-38 vented \\
Wall Insulation & Concrete Block, R-10 board \\
& insulation \\
Ventilation & 25 CFM (runtime) \\
Windows & U=0.55-0.26, \\
& SHGC $=0.7-0.18$ \\
\hline
\end{tabular}

Challenges that Ravenwood experienced when building its first high-performance home included the following:

- Insulation installation. Miscommunication between the insulation installers and the builders and inexperience with high-performance building resulted in improper insulation installation that required last-minute corrections before the drywall could be installed. During the midpoint Thermal Bypass Inspection, which is required for Energy Star V3 certification, the wall insulation was found to be inset stapled. Inset stapling leaves gaps between the insulation and the drywall, creating a tunnel through which air and heat can flow. Insulation should always be in full contact with the drywall. Based on this mistake, the builder had come back to reinstall all of the insulation in the home before the sheetrock crew was scheduled to arrive the following day. However, proper installation could not be confirmed by the HERS rater in the short time frame, so the HERS rating suffered. ${ }^{1}$

- Contractor experience. For many of the contractors and builders, this was the first highperformance home with a PV system and ducts in conditioned space. This fact resulted in scheduling confusion and lack of attention to details on many high-performance measures. For example, building ducts below the ceiling plane in framed chases is an important aspect to minimize duct leakage and maximize comfort. However, Ravenwood did not fully comprehend how implementing ducts below the ceiling plane would affect the construction schedule and did not fully educate the field workers responsible for doing the work, which is crucial to achieving success.

\footnotetext{
${ }^{1}$ Not being able to verify insulation quality, the rater gave the insulation a Grade 3 .
} 
- Cost Issues. Building a high-performance home cost-effectively requires good scheduling of tradespeople to minimize wasted time, and maximize attention to detail. Due to confusion and lack of understanding on the part of the tradespeople, which can be expected on a builder's first attempt, the cost of this home was higher than it could have been. To save on costs, a lower SEER airconditioning system and downsized PV array were installed than were originally recommended in the design, both of which contributed to the home's $>0$ HERS rating.

Ravenwood's experience with high-performance building resulted in many lessons learned, including the following:

- Training is important for the installer to achieve best practices. Involving the builder, designer, and building science consultant in the training of all onsite workers can help meet efficiency goals by ensuring all trades know what is expected of them and when. This can also minimize delays and wasted time re-doing work, minimize cost.

- Design decisions made in the field can dramatically influence energy performance. Every detail counts when building a net zero energy home; several design modifications that were made in the field on Ravenwood's first net zero energy home resulted in a greater than zero HERS. These include installing 57 additional can lights than were originally specified in the design, the addition of a swimming pool pump, downgrading the AC system, and installing a smaller PV array.

All things considered, Ravenwood's first attempt at a net zero energy home with ducts in conditioned space was fairly successful; it achieving a HERS score of 15. Unlike other builders, Ravenwood did not take baby steps toward high performance and, as

Ravenwood applies lessons learned from this first home to other projects, it will soon be building some of the best performing, cost-effective homes in the nation. Ravenwood's business model now focuses primarily on building high performance and net zero energy homes.

\subsection{Sage Homes, Inc.}

Sage Homes is a small, family-owned business in Florida that was founded in 2000 and employs 3 staff. Recent work has focused on remodels ( 2 to 4 projects per year), with some new construction ( 2 to 3 homes per year) as well. Building energy-efficient, high-performance homes helps Sage Homes gain a market advantage in its area and remain competitive with other builders. The low and predictable utility bills also attract its primary customer base, who are mostly retirees living on fixed incomes and appreciate the lower energy costs for high-performance homes.

Sage Homes has built high-performance homes in the past, achieving a HERS 55 rating on a previously constructed home and earning multiple awards for the high-performance results. Sage Homes typically uses spray polyurethane foam-sealed attic systems to incorporate ducts in conditioned space, while accommodating client-requested recessed ceiling lights, and to prevent any chance of condensation formation on ductwork. However, in late November, Sage Homes approached Calcs-Plus for assistance on a current home design for a long-time client who did not want to use spray foam in the attic. Given 
that this home was already designed, under contract, and permitted, only half of the duct system could be placed in dropped soffits; the rest needed to be placed above the ceiling for design and aesthetic reasons, as indicated in Figure 9.

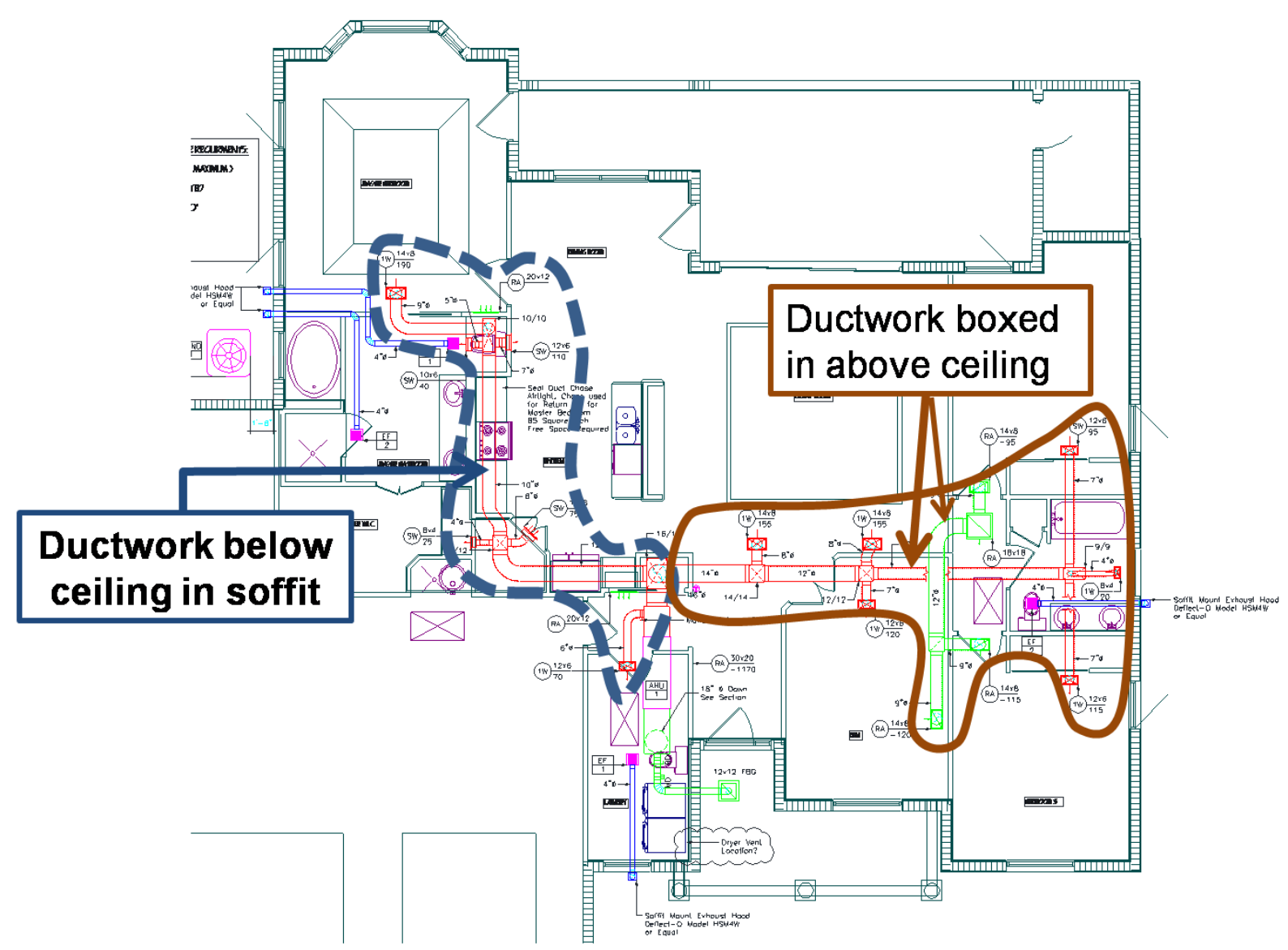

Figure 9. HVAC Duct Layout for Sage Homes High-Performance Home.

Sage Homes still wanted to place all ducts within conditioned space, so they decided to build insulated chases around the ducts located in the attic, even though this design choice would be labor intensive and expensive. To achieve this modified design, the HVAC contractor built custom insulated chases, consisting of rigid board insulation and R-30 batt insulation, around the ductwork installed in the attic. The attic duct chase is depicted in Figure 10.

Vent holes were placed in the ceiling to prevent pressure differences between the duct chase and the conditioned space. This unique application of ducts in conditioned space was the primary reason that Sage Homes was added to this study. The home has an expected construction completion date of midApril 2013.

In addition to the ducts in conditioned space, the home incorporates other high-performance features summarized in Table 6. 


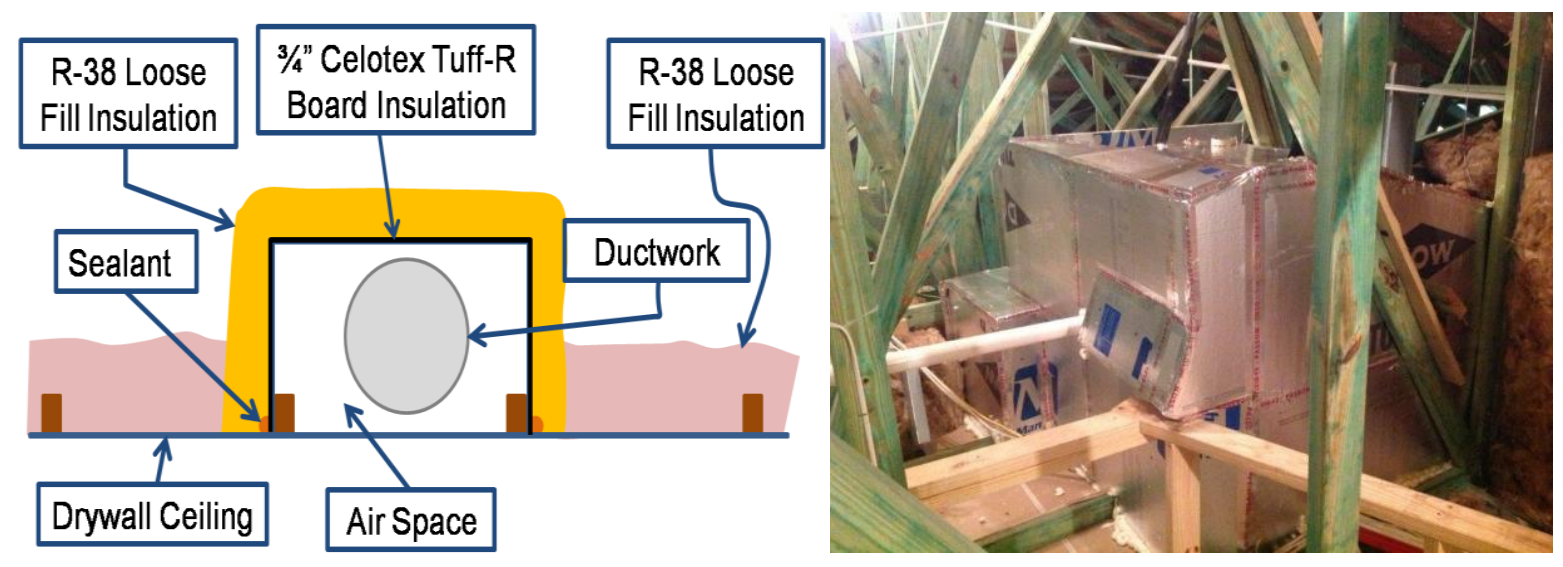

Figure 10. Left: Design of Above Ceiling Attic Duct Chases; Right: Implementation of Duct Chase in the Field.

Table 6. Sage Homes Home Characteristics

\begin{tabular}{lc}
\hline \multicolumn{1}{c}{ Characteristic } & Home \\
\hline HERS Rating (Initial) & 65 \\
Size $\left(\mathrm{ft}^{2}\right)$ & $2,123 \mathrm{ft}^{2}$ \\
Climate Zone & Hot-Humid \\
Building Leakage (ACH50) & Not yet completed \\
Duct Leakage (CFM25 out) & Not yet completed \\
Heat Pump & 19 SEER/10 HSPF \\
Water Heater & Electric storage \\
Attic Insulation & R-38, vented attic \\
Wall Insulation & R-13, 2x4 framing \\
Ventilation & Run-time ventilation \\
Windows & U=0.3, SHGC $=0.21$ \\
\hline
\end{tabular}

Challenges that Sage Homes experienced when building their first high-performance home included the following:

- Communication with tradespeople is crucial. One of Sage Homes' primary challenges was communication with and training of the tradespeople. Because the boxed-in ductwork was a field modification, proper coordination and education was not possible. This made key subcontractors confused and uncooperative. "I got a lot of push back, especially from my metal stud framer," reports Paul Shaefer, president of Sage Homes, "even though this is common in commercial and the subs have commercial experience." Paul cited a lack of communication and lack of detailed drawings as slowing things down and making them "more complicated than they needed to be."

- Insulation installation. Despite Sage Home's experience with high-performance construction, and the fact that the company specifies face-stapled insulation in the contract and statement of work for the insulation installers, the midpoint Thermal Bypass Inspection identified insulation attached on the inside of steel-stud framing on the adjacent walls (between the conditioned space and the garage), as shown in Figure 11. 


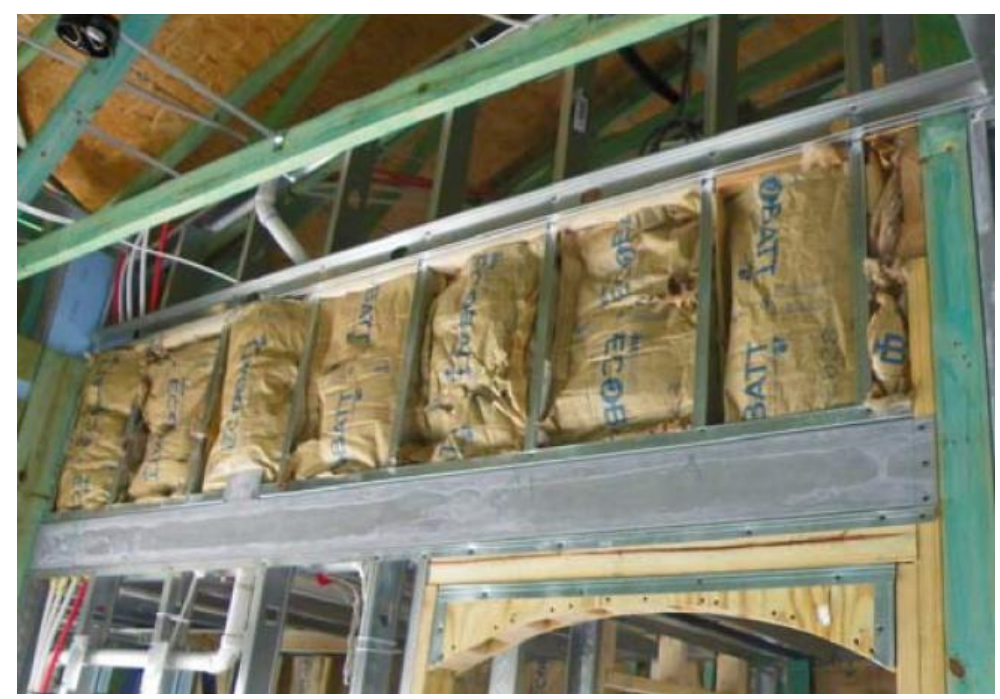

Figure 11. Inset Steeled Batt Insulation on Adjacent Walls Between Garage and Living Area as Identified during Thermal Bypass Inspection

When confronted about the issue, the insulation installer was familiar with face-stapling and reinstalled all the insulation properly, but without the Thermal Bypass Inspection the builder and the homeowner would not have received the performance they had specified and paid for.

Sage Homes' lessons learned regarding high-performance building include the following:

- Midstream design changes can be difficult and costly. Installing the insulated chases around the ducts in the attic required much time and money. Ideally, the decision to place ducts in conditioned space below the ceiling would have been made early in the design process so the additional cost and time could have been avoided. It was Sage Home's commitment to both customer service and highperformance building that resulted in this a-typical solution. Once the home is completed, the actual home performance will indicate whether the additional measures successfully affect energy use. As it was, Paul constructed attic duct chases around plumbing, electrical, and vent stacks, which was not ideal. "Had the house been designed for it, it would have been much easier," he admits. Having a clear path forward from the start of construction might also have improved coordination and cooperation of the tradespeople, and allowed for more training opportunities as needed.

- Attention to detail is still important for an experienced high-performance builder. Sage Home's challenges with proper insulation installation illustrates that proper education and specification in contracting documents may not be sufficient to ensure proper installation; attention to details must include follow through on the part of the builder to inspect installation jobs (or have them inspected as part of the Thermal Bypass Inspection) to confirm proper installation and construction quality. Most likely, this applies to air sealing as well. Paul has also used and planned for a "last chance airsealing" opportunity, which can help remedy any construction defects and ensure an airtight and thermally aligned envelope.

- A credentialed HVAC contractor is required for Energy Star certification. Based on existing trade relationships, Sage Homes chose to use a non-credentialed HVAC installer, but will still fill out the Energy Star HVAC check list. Sage Homes believes the home will achieve as good or better performance, but because the HVAC installer is not certified, the home does not qualify for Energy Star certification or DOE Challenge Home status. 
- Importance of education. Sage Homes also emphasizes the importance of education in furthering high-performance home construction. Educating homeowners or perspective customers is one of the biggest challenges, according to Sage Homes president Paul Shaefer. He is currently working on a project to document total monthly cost of ownership ${ }^{1}$ from high-performance versus conventional homes, to help inform homeowners about how an incremental investment in a home's efficiency can pay off over time.

Previously, Sage Homes has used spray foam in unvented attic assemblies to bring ducts into the conditioned space. However, Paul's dedication to the importance of ducts in conditioned space from an energy and comfort perspective, and this homeowner's aversion to spray foam, led him to use an unusual and complicated approach. Despite the difficulties encountered on this first home, Sage Homes will continue to consider building homes with ducts below the ceiling plane, if it is part of the design from the beginning.

"I like the idea [of ducts below the ceiling plane] from a cost savings perspective, since spray foam is expensive. You need to get the trades on board. I know some builders who have made it cost the same or less, I just need to get there."
Paul Schaefer, President Sage Homes, Inc.

\subsection{Sun Energy Homes}

While Sun Energy Homes is a newer company, owner Frank Young has been in the home construction industry for years, and has built about 5,000 homes during his career. the company's market had historically focused on first-time homebuyers for whom energy efficiency was not a primary goal. Wanting to differentiate itself from other builders, Sun Energy Homes decided to pursue highperformance homes in 2011. Its first high-performance home has been designed and is scheduled to begin construction in spring/summer 2013. This home is $2,788 \mathrm{ft}^{2}$ and will feature insulated CMUs, highperformance air conditioning, and ducts in conditioned space. Table 7 summarizes the home characteristics as designed.

Table 7. Sun Energy Home Characteristics

\begin{tabular}{lc}
\hline \multicolumn{1}{c}{ Characteristic } & Home \\
\hline HERS Rating (Initial) & 74 \\
Size $\left(\mathrm{ft}^{2}\right.$ ) & 2,778 \\
Climate Zone & Hot-Humid \\
Building Leakage (ACH50) & $3.5^{(\mathrm{a})}$ \\
Duct Leakage (CFM25 out) & $84^{(\mathrm{a})}$ \\
Heat Pump & 16 SEER/electric strip heating \\
Water Heater & 40 gallon electric, EF $=0.92$ \\
Attic Insulation & R-38 \\
Wall Insulation & CMU R-5 \\
Ventilation & Run-time vent \\
Windows & $\mathrm{U}=0.30 /$ SHGC $=0.20$ \\
\hline
\end{tabular}

(a) Estimated; home has not yet undergone final air leakage testing

\footnotetext{
${ }^{1}$ Total monthly cost of ownership represents the monthly mortgage payment (Principle, interest, tax, and insurance [PITI]) plus energy costs (utility bills).
} 
Sun Energy estimates that this high-performance home will cost less to build than other standard designs. However, Sun Energy Homes encountered some differences from conventional home building while designing this home, including the following:

- Adjustments to the standard process for contractors. Because high-performance building requires different processes than typical home construction, Sun Energy expects there will be some adjustments for contractors (e.g., running drywall before electrical), but does not anticipate that any of these changes will be major challenges to achieving the expected results. The HVAC designer was not accustomed to designing ducts in conditioned space, but the long working relationship with Sun Energy Homes helped make the transition to the new process smoother.

Sun Energy Home's lessons learned during the design process included the following:

- Reapply savings from reduced mechanical systems to more costly high-performance features to reduce the overall cost. One of Sun Energy's primary goals was for the high-performance home to be cost-effective compared to the company's standard design. Sun Energy achieved this goal by applying savings from design changes such as reduced HVAC size for the high-performance home (2.5 tons compared to the standard design's 5-5.6 tons) and shorter duct runs, to more costly design changes such as advanced framing and windows.

- Use relationships with contractors, volume purchasing experience, and design trade-off knowledge to further reduce the overall cost. These factors helped Sun Energy Homes achieve a cost-effective design, estimated at $\$ 92 / \mathrm{ft}^{2}$. Sun Energy is the first high-performance builder ESHP has worked with that has reported lower costs per square foot for high-performance homes than standard designs. However, it will be important to account for the additional labor costs required to achieve tight envelope construction into the final cost to build high-performance once the home is complete.

While the final performance of the home will not be known until construction is complete and the home is occupied, Sun Energy expects that the results will be consistent with the plans, and is eager to begin construction on the home. Given its positive experience so far and the demand for high-performance in their area, Sun Energy plans to continue building highperformance homes as long as the costs remain competitive with standard designs.

"Building high performance homes is not only the right thing to do, but it also costs less, with costs lower per square foot than what I've built up to now."

Frank Young, Partner Sun Energy Homes 


\subsection{Lessons Learned and Best Practices}

The builders featured in this study cover two climate zones, three states, and span a wide range of experience with high-performance homes, from builders who have been building high-performance homes for over a decade to builders who have just entered the high-performance market within the last few years. While each builder's experience with high-performance construction methods varies, the project team observed lessons learned common to many of the builders. These lessons learned include design challenges, implementation challenges, and lack of understanding of the HERS scoring methodology.

\subsection{Design Challenges: Plan for Success}

Many builders noted the need to identify high-performance goals and construction techniques at the design phase. Some aspects of high-performance building, such as installing ducts in framed chases below (or above) the ceiling plane to bring them into conditioned space, can occur much more smoothly and for less cost if they are included in the design of the home and planned for from the beginning. Sage Homes experienced the difficulty associated with design aspects not being included or planned for from the beginning when the homeowner requested no spray foam be used in the home and the original sealed attic design had to be modified; the builder had to box in some ducts above the ceiling plane and some ducts below the ceiling plane to keep the ducts in conditioned space.

Some traditional home designs are not well-suited to the central and linear design that works best for incorporating ducts below the ceiling plane, as G.W. Robinson noticed when considering ducts in conditioned space for its Classic home designs. As a result, ESHP encourages builders interested in pursuing ducts in conditioned space to design a new plan with the HVAC system layout in mind, or consider an ESHP design that has already considered HVAC location and layout in all its plans.

In addition to thoughtful design, successful high-performance home construction also requires advanced planning, because some steps may occur in a different order than typical building (e.g., drywall before ducts installed for ducts in conditioned space) and require multiple trips by some tradespeople. Sometimes tradespeople resist new methods and construction schedules, especially the decreased flexibility and increased attention to detail that are inherent in some high-performance building practices (e.g., less flexibility to change ducts in conditioned space and less flexibility to change plumbing layouts with slab flooring).

Many builders cited difficulty training and indoctrinating tradespeople in new high-performance construction methods and practices. Some of the most common difficulties were implementing dropped soffits for ducts below the ceiling plane and proper insulation installation. Successful builders, such as G.W. Robinson, benefited from the presence of another local high-performance builder who has already transitioned some of the tradesmen, so the concepts were not entirely new. Also, G.W. Robinson used a pre-build team coordination meeting, which brought all the tradespeople together with the site construction manager and the builder to discuss the overall design, construction schedule (including any changes), and any important details that would be key to a successful design. G.W. Robinson also made sure the tradespeople knew that this would be a more flexible job as they tried out this new construction method. Engaging tradespeople in the overall process from the beginning made them much more cooperative in trying new techniques and more flexible when a few changes had to be made. 
Sage Homes noticed that even though some of its subcontractors had experience with similar construction methods in commercial applications, they had trouble visualizing how the design would be implemented in a residential setting. Detailed construction drawings, photographs, and guides specifying soffit construction, location, and installation guidelines would have been helpful in communicating with tradespeople who were unfamiliar with the design.

In addition, Sage Homes modified its construction schedule to provide an opportunity to compensate for less than perfect installation jobs. Sage Homes ensures that the homes' air boundary and ducts are tight by walking the attic with a foam gun and caulk to catch any holes that may have been left or created by tradespeople prior to covering up the attic ceiling with insulation. This "last change air sealing" opportunity is a good best practice, which can be made even better by use of a blower door and smoke, if available, but must be accounted for in the construction schedule, prior to when the insulation truck arrives. Ravenwood Homes could have benefited from this best practice at a different key time, after the Thermal Bypass Inspection. Builders should set aside time to correct issues identified by the Thermal Bypass Inspection, such as inset stapling, before sheetrock is installed. Also, if a home is being rated, the builder needs to account for a return trip by the HERS rater to verify any corrections or else the changes cannot be accounted for in the HERS rating.

\subsection{Implementation Challenges}

Builders encountered challenges and developed best practices related to accountability and attention to high-performance details on the job site, and encountered difficulties related to geographic and regional constraints.

\subsubsection{The Devil Is in the Details}

Attention to details is required to translate high-performance plans into high-performance results. Several of the builders participating in the program struggled to achieve the requisite level of attention in the field. Clear roles and responsibilities are required to ensure no important details are missed or overlooked. The best way to articulate roles and responsibilities is in the contracting documents. Being clear in contracting documents about the expectation that tradespeople seal any air barrier penetrations and install systems properly (e.g., no inset stapling for insulation) is a great way to articulate roles and responsibilities, especially regarding new construction practices like installing ducts in conditioned space.

After expectations are clearly articulated in the contract documents, training and communication with tradespeople is necessary, especially for subcontractors new to high-performance building. Going over these contract documents with tradespeolpe, including drawing on additional diagrams or photos to aid in comprehension, is important to confirm that subcontractors understand differences in high-performance versus typical building. Then, demonstrations in the field or direct oversight during the initial phases of a task, can help solidify understanding and ensure new construction techniques are put into practice.

However, proper education and specification in contracting documents may not be sufficient to ensure proper installation. As Sage Homes learned, attention to details must include follow-through on the part of the builder to inspect installation jobs (or have them inspected as part of the Thermal Bypass Inspection) to confirm proper installation and construction quality. Heritage Buildings has also applied this method to air sealing with great success. Heritage makes one person (perhaps the builder) on the job site responsible for walking the entire house with a can of spray foam and caulk to seal any remaining holes to ensure a tight building envelope. 


\subsubsection{Results May Vary}

Several builders learned that flexibility is important, because specific geographic or regional market constraints will affect what the best high-performance building solution is in a given location. Highperformance homes do not have to cost significantly more to design and build than conventional homes, but several factors will influence the cost and availability of resources.

First, as with any building, physical constraints of a site will dictate the best foundation and orientation for a high-performance home, while making other high-performance strategies difficult or impractical to implement. For example, BWB's varied topography and soil characteristics required more site preparation to prepare for the raised concrete slab, resulting in additional cost. Choosing foundation and construction types that are appropriate for each site's specific geographic characteristics will result in an easier, less costly construction and could lead to increased durability as well.

In addition, the prevalence and acceptance of new, high-performance home construction methods in a specific region will depend on the familiarity of the local trades and suppliers. For example, highperformance homes are not very common in Tennessee where BWB builds, so there are experienced contractors and materials are fewer, making the latter more expensive to acquire. Therefore, builders must be allowed the flexibility to be creative in achieving high-performance homes. In Tennessee, BWB implemented a stick-built raised heel truss, because engineered trusses were not available. In some regions, certified HVAC installers are not widely available and, thus, it is more difficult to certify a home under the Energy Star label, even if the HVAC system is designed and installed properly.

The experience of a region with high-performance housing also affects the availability of support systems that help a builder construct, certify, and sell high-performance homes. The proximity of builders to building science resources, like raters, makes it easier to provide more frequent, one-on-one support. This can help builders address design challenges and certification issues as they arise. When these technical resources are not available, especially when designs are changed in the field, the result is usually increased costs, decreased performance, or both. Builders should actively pursue local building science support when making design changes to help make their first high-performance home a success. It should be noted that building science support is not required to achieve a successful high-performance home on the first attempt, as Heritage Buildings has demonstrated by not making extensive modifications to the design and having good attention to details. However, engaging with a building scientist allows for quicker learning and transfer of building science best practices, which reduces risk and can help optimize the construction process to save time and money, without sacrificing performance.

Lack of experience with high-performance homes in a region can also result in code issues, where code inspectors are not familiar with high-performance techniques. For example, BWB's stick-built raised heel trusses were not accepted by the code official. In some cases, building science support or clear technical resources can help builders resolve code issues.

\subsubsection{Market Demand Varies}

Builders also noted differences in market demand for high-performance homes as a challenge, as well as the importance of educating homeowners about the value of high-performance homes. While some of Heritage Buildings' customers are very interested in high-performance building (the company's first ESHP-designed home was initiated by customer request), Heritage believes that the majority of its current 
customer base is hesitant to invest in a truly high-performance home. However, Heritage believes that a changing demographic will translate into more customers being attracted to the lifetime cost savings and other benefits of a high-performance home. Heritage now employs two individuals who have been trained specifically to explain and market high-performance features to potential homebuyers.

Sage Homes and Josh Wynne Construction have taken a more proactive approach, emphasizing educating homeowners and perspective customers about the benefits of high-performance, including total monthly cost of ownership, increased comfort, improved indoor air quality, increased durability, and improved regional environmental impact. According to Josh Wynne, "every client wants a sustainable home; some clients require an education to make them realize that." Total monthly cost of ownership, with represents the total amount of money a homeowner must devote to owning a home monthly, including all mortgage related payments (principle, interest, tax, and insurance [PITI]) plus monthly energy costs (utility bills). For high-performance homes, total monthly cost of ownership can be less than for conventional homes, as the savings from utility bills can be greater than the incremental capital cost reflected in the mortgage payment.

\subsection{Certification Challenges}

Finally, builders also expressed confusion related to the HERS methodology and how HERS ratings related to the actual energy use of their homes.

\subsubsection{Deciphering the HERS "Black Box"}

Some builders wanted to better understand how specific design characteristics or trade-offs between specific high-performance measures would affect the home's energy use and HERS score. Construction decisions always involve a cost-benefit analysis. Builders typically have good cost information from their suppliers, but do not always have good information about how a specific design decision will affect overall home performance. For example, although BWB's site conditions were more appropriate for crawlspace construction, BWB chose to use a raised slab foundation because it was unsure how moving to a crawlspace would affect the completed home's performance and HERS rating.

\subsubsection{HERS Accuracy for High-Performance Homes}

Heritage Buildings and Josh Wynne Construction both found that their completed homes consistently performed better than their HERS score predicted. For example, in Heritage's first home, the home's actual performance has been $40 \%$ lower than the HERS rating of 56 would predict, using just 8,075 $\mathrm{kWh}$ annually as opposed to the HERS-predicted $12,280 \mathrm{kWh}$. This discrepancy could be due to a "conservation bias," where the homeowners in high-performance homes are inherently more conservative in their energy use, or it could be due to some building feature that has greater impact than is being captured by the HERS rating, either because of inherent energy savings or a secondary effect because of improved comfort.

Anecdotal evidence suggests that this trend is specific to high-performance homes with HERS scores of about 55 or below. Relevant to this study, Heritage noted that a very similar neighboring home (HERS 86) was also rated and exhibited energy consumption within $4 \%$ of the energy consumption estimated by the HERS rating system. A survey of the high-performance Heritage home and very similar neighboring home showed that the two homeowners operated their homes in similar ways, which suggests that in this 
case homeowner preferences were not a primary driver for the better-than-expected home performance. To investigate this further, PNNL created energy models using EnergyGauge USA to predict the energy use for each home, with and without accounting for customized occupancy information and equipment schedules gathered in a homeowner survey. PNNL compared the estimated energy use from EnergyGauge USA with and without accounting for occupancy to estimate the relative impact behavior changes had on energy use for these two homes. PNNL also compared the EnergyGauge USA energy use estimates to those from the HERS rating and the annual utility bills from both homes, shown in Figure 12.

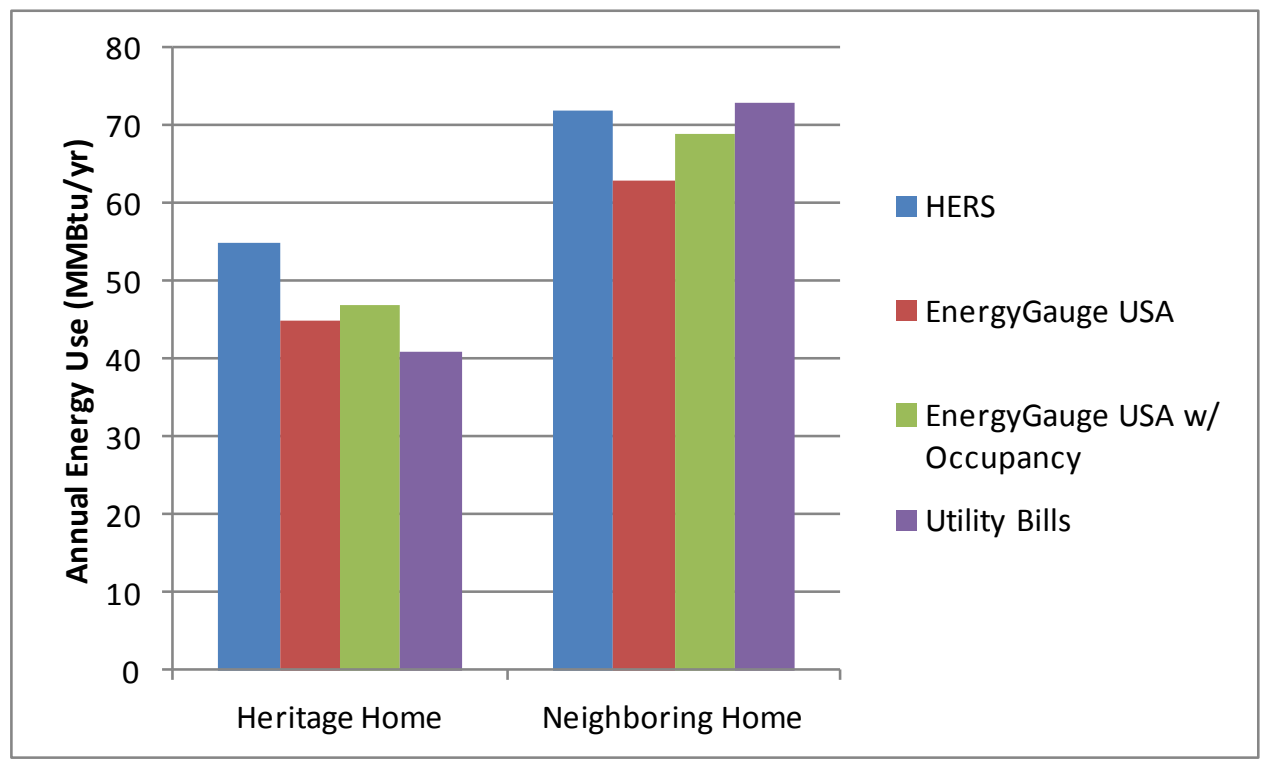

Figure 12. Estimated Annual Energy Use (Million British Thermal Units per year [MMBtu/yr]) for the Heritage Home and the Neighboring Home Based on the REMRate Generated HERS Rating, EnergyGauge USA Also Using HERS Defaults, EnergyGauge USA Accounting For Specific Occupancy Factors and Homeowner Behaviors, and Utility Bills.

Based on this two-home analysis, occupancy does not appear to account for the discrepancy between the predicted energy use based on the HERS rating methodology and the utility bills and actually increased energy use in both the EnergyGauge USA simualtions. Notably, the energy use estimates generated using REMRate and that generated using EnergyGauge USA were not consistent. The reason for this was not resolved as part of this project, but indicates a need for a better understanding of the variables that impact the accuracy and precision of HERS rating.

Due to this inconsistency, as well as the perceived ambiguity regarding how specific home characteristics or energy-efficiency measures affect the homes HERS rating, Heritage Buildings is disinclined to rely on HERS ratings to evaluate or market his homes. Heritage Buildings owner Vic Sikka has observed that high-performance Heritage homes consistently use less energy than their HERS scores would predict, and believes that a home's utility bills are a more straightforward and reliable way to communicate performance.

\subsubsection{DOE Challenge Home}

Participating builders were encouraged, but not required, to certify their homes to the DOE Challenge Home level and a "DOE Challenge Home Plan Set" was prepared (attached as Appendix C). However, 
the home depicted and specified in the DOE Challenge Home Plan Set was not built, in its entirety by any of the participating builders, and only one builder (Josh Wynne) chose to pursue DOE Challenge Home certification. After interviewing several of the builders, it appears that the specific requirements of DOE Challenge Home were not fully understood. This points to the need for better and more succinct ways of communicating the DOE Challenge Home requirements to builders.

In preparing the DOE Challenge Home Plan Set, PNNL and ESHP observed that the detailed list of specification may not be the best way to communicate the DOE Challenge Home requirements to builders because they appear overwhelming and require multiple links to other documents. When and if plans become digital documents, a list of detailed specifications, such as those provided in Appendix C, may be more appropriate. In the meantime, the "checklist approach," which has been adopted by Energy Star may be successful for describing to builders exactly what is required in a straight-forward manner. However, based on the difficulty builders in this study had with interpreting the requirements and guidance they received, customized checklists may have more success than simply referencing pieces of existing checklists.

Notably, many builders believed they were already doing many of the items, primarily related to airsealing, insulation, and moisture management. However, most builders struggled with the Indoor airPLUS requirements related to low-emission materials, the Energy Star Version 3 requirement that a certified HVAC contractor complete the HVAC System Quality Installation Contractor Checklist, and the requirement to provide ventilation systems capable of providing the level of ventilation specified by ASHRAE $62.2^{1}$. These areas will require the most technical assistance and resources for builders wishing to transition to DOE Challenge Home.

\footnotetext{
${ }^{1}$ ASHRAE was previously referred to as the American Society of Heating, Refrigeration, and Air-Conditioning Engineers, but is not
} 


\subsection{Conclusions and Recommendations}

Based on the experiences of these seven builders, high-performance homes are possible, but can be challenging to implement, especially for the first time. While all of the participating builders were implementing some aspect of high-performance homes for the first time, experience ranged from Builders Challenge builders implementing ducts below the ceiling plane for the first time, to builders making the leap from strictly conventional construction practices. Despite this variation in experience, the builders shared common challenges and could benefit from similar resources and information. Helpful resources include the following:

- Design resources and guidance regarding best construction practices in each climate. Highperformance homes start with a good design. Guidance for builders about the key elements, such as ducts in conditioned space, advanced framing, and plumbing layout, are needed as are example plan sets. Also, high-performance designs must be flexible to address regional constraints. Information regarding the "best" design guidance for each climate will help builders make informed decisions about which elements are critical to a high-performance home and which can be more flexibly addressed.

- Guidance for builders about key changes that result from moving to high-performance home building. Builders need guidance with a specific focus on schedule impacts. Lots of resources exist that provide good information about what to do (e.g., BA Solution Center; basc.energy.gov), but less information is available about how changes related to high-performance building affect a builder's day-to-day construction schedule. While how a builder implements energy-efficiency measures on a specific job site will vary and explicit guidance may not be widely applicable, an example "case study" on schedule impacts could help builders better anticipate the biggest differences between highperformance and conventional building. For example, the differences include the need to schedule duct installation before drywall goes up and the need to account for a midpoint Thermal Bypass Inspection (and sufficient time to address any necessary changes).

- Resources for builders to communicate with and educate the tradespeople. Many builders cited the need for clear and concise examples of construction techniques to help communicate with tradespeople. The BA Solution Center is a new resource that includes guidelines for many highperformance construction practices, including step-by-step installation instructions, contract language, relevant code issues, climate considerations, computer-assisted design (CAD) drawings, and images. As the BA Solution Center grows and additional content is added, it should meet most builders' needs for resources for communicating with subcontractors about proper installation and verification techniques. However, additional effort is needed to make builders aware of this resource and help them navigate through the content.

- Information regarding the relative impact of design trade-offs on HERS scores. To optimize an energy-efficient design, builders need information about the cost and expected performance of different components. Some smaller, less experienced builders do not have a good understanding of how different design decisions affect a home's HERS score, which makes performance trade-offs more difficult. For example, a builder may be interested in how putting in better windows, but installing a less efficient water heater, will affect the HERS score. This can be solved if builders have a good working relationship with a local building scientist, who can perform what-if modeling for them. If local building science support is not available, general information regarding the most important contributors to the HERS score would help builders make informed decisions regarding the 
costs and benefits of certain design decisions. Builders could save money on technical assistance if general information regarding what home characteristics affect the HERS rating the most, or how many "points" were associated with different building components, were available without the need for detailed modeling.

In addition to identifying the need to have access to more and better resources and tools, this project identified several areas where additional research is needed to answer outstanding questions. These areas include the following:

- Research on HERS accuracy for high-performance homes. Several builders in this study noted that low-HERS-score homes were consistently performing better than their HERS scores predicted. A pilot study based on two homes, the Heritage Buildings home and neighboring HERS 86 home discussed in section 4.3.2, suggests that homeowner behavior may not be the only reason for this discrepancy and there may be other home characteristics that are not being fully addressed by the HERS rating methodology. However, to bring significance to the finding, performance data derived from more homes are needed. With additional large data sets of HERS-rated homes and utility bills, researchers could develop a larger, detailed data set of home characteristics, HERS scores, and utility bills to identify key factors that affect the accuracy of the HERS score for high-performance homes in the sample.

- Research on ducts in conditioned space. As one of BA's Top 10 Innovations (DOE 2012), the installation of ducts in conditioned space is becoming widely accepted as a building science best practice and recognized as necessary for a home to truly be high performing. However, there are several methods for installing ducts in conditioned space and confusion exists as to the relative performance of the different methods. Methods for installing ducts in conditioned space include a spray foamed, unvented attic assembly; ducts in dropped soffits below the ceiling plane; ducts in specially designed chases in the attic, which are passively connected to the conditioned space; ducts in an unvented crawlspace or conditioned basement; and ducts encapsulated in spray foam and buried in attic insulation or ducts deeply buried in insulation. The relative performance of each of these methods is not well understood.

As the experiences of these seven builders have demonstrated, affordable, high-performance homes are possible, but require attention to details and flexibility in design to accommodate specific regional geographic or market-driven constraints that can increase cost. With better information regarding how energy-efficiency trade-offs or design choices affect overall home performance, builders can make informed decisions regarding home design and construction to minimize cost without sacrificing performance and energy savings. 


\subsection{References}

DOE (U.S. Department of Energy). 2012. "Building America's Top Innovations Advance High Performance Homes: Ducts in Conditioned Space." Washington, D.C. Available at:

http://www1.eere.energy.gov/buildings/residential/ba innovations.html

DOE (U.S. Department of Energy). 2013. "DOE Challenge Home.” Washington, D.C. Available at: http://www1.eere.energy.gov/buildings/residential/ch_index.html

EPA (U.S. Environmental Protection Agency). 2012. "ENERGY STAR Qualified Homes, Version 3 (Rev. 06) National Program Requirements." Washington, D.C. Available at:

http://www.energystar.gov/ia/partners/bldrs lenders raters/ES Combined Path v 65 clean 508.pdf?e6 $\underline{88-\mathrm{e} 520}$

EPA (U.S. Environmental Protection Agency). 2013. "Indoor airPLUS Construction Specifications: Version 1 (Rev. 01).” Washington, D.C. http://epa.gov/indoorairplus/pdfs/construction specifications.pdf

IECC (International Energy Conservation Code). 2012. International Code Council, Washington, D.C. Available at: http://www.iccsafe.org/Pages/default.aspx

NAHB (National Home Builders Association). 2013. "Home Trends \& Buyer Preferences." Presentation at the 2013 NAHB International Builders' Show. Las Vegas, Nevada. Available at: http://www.nahb.org/fileUpload_details.aspx?contentTypeID=3\&contentID=195206\&subContentID=493 $\underline{454}$.

PNNL. 2011. "Building America Case Study: Initial Performance of Two HERS <0 Homes." PNNL-SA-84975, prepared by the Pacific Northwest National Laboratory for the U.S. Department of Energy Building America Program. Available at:

http://apps1.eere.energy.gov/buildings/publications/pdfs/building america/tommy williams two zero en ergy_homes.pdf

PNNL. 2012. "Building America Case Study: Tommy Williams Homes, Longleaf Village \& Belmont, Gainesville, FL." PNNL-SA-87331, prepared by the Pacific Northwest National Laboratory for the U.S. Department of Energy Building America Program. Available at:

http://basc.pnnl.gov/sites/default/files/casestudies/Final_BA_NewResidentialCS_TommyWilliams_042412.pdf 



\section{Appendix A}

Complete List of New Home Builders 

Table A.1. Complete List of Builders Contacted as Part of New Homes Project

\begin{tabular}{llccc}
\hline \multicolumn{1}{c}{ Builder Company } & Builder Name & ESHP & Homes & Location \\
\hline & Builders Participating & in Program & & \\
\hline Josh Wynne Construction & Josh Wynne & No & 1 & Sarasota, FL \\
Ravenwood Homes & Dave Wishtischin & Yes & 1 & Cape Coral, FL \\
Big Whiskey Builders & Rick Harris & Yes & 2 & Chattanooga, TN \\
Sun Energy Homes & Frank Young & Yes & 1 & Stuart, FL \\
Heritage Homes & Vic Sikka & Yes & 7 & Wilmington, NC \\
G.W. Robinson & Gay Robinson & Yes & 4 & Gainseville, FL \\
Sage Homes Inc. & Paul Schaefer & No & 1 & Port Charlotte, FL \\
\hline & Builders Not Moving & Forward & & \\
\hline Florida Bay Builders & Greg Fishell & Yes/New & 1 & Marco Island, FL \\
Choose the Right Construction & Melvin Boyce & Yes/New & 15 & Goshen, IN \\
Green Castle Inc. & Shawn Harvey & Yes & 1 & Naples, FL \\
Coastal Development and Services & Ken Belshe/ & Yes/New & 21 & Victoria, TX \\
Company & Darryl Hammond & & & \\
Brown and Meers Homes & TJ Meers & Yes & 1 & Madison, AL \\
Bart Liddon Homes (builder) & Bart Liddon & No & 1 & Dothan, AL \\
Custom Home Designs (designer) & & & & \\
\hline
\end{tabular}





\section{Appendix B}

\section{New Home Case Studies}





\section{BUILDING TECHNOLOGIES PROGRAM}

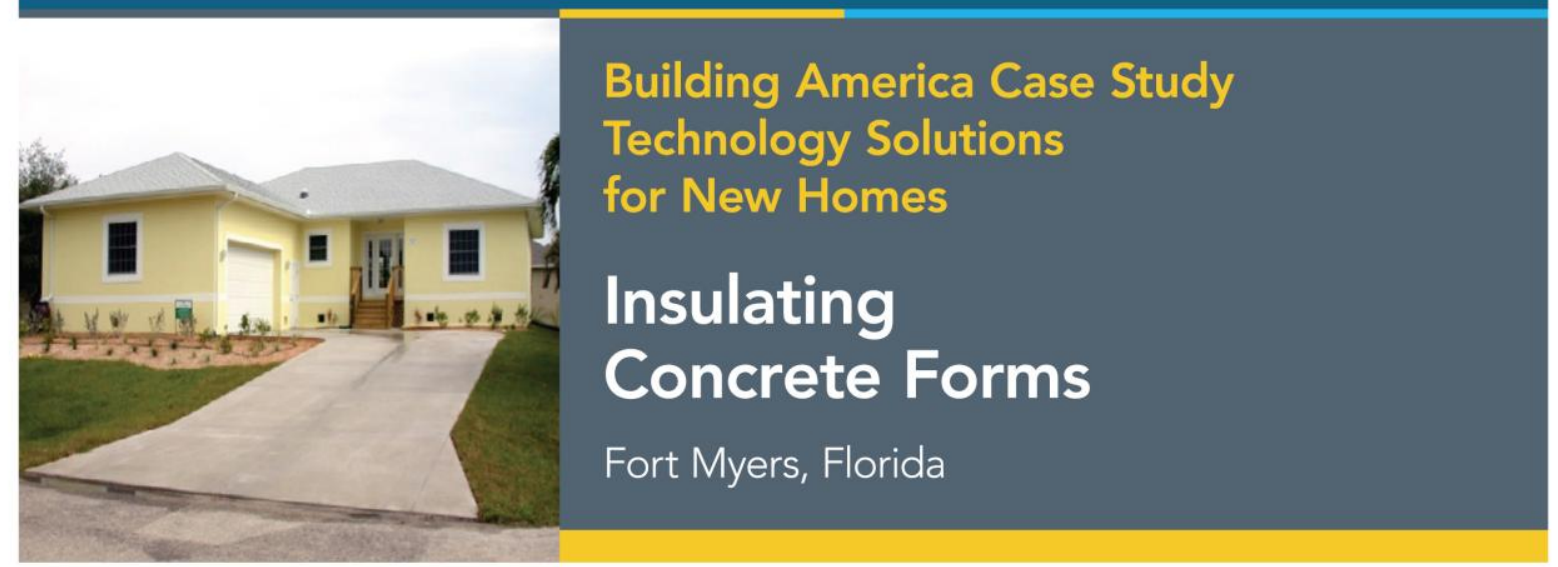

\section{PROJECT INFORMATION}

Project Name: Sandalwood

Location: Fort Myers, FL

Size: $1,964 \mathrm{ft}^{2}$

Partners:

Pacific Northwest National Laboratory www.pnnl.gov

Greencastle, Inc.

www.greencastleinc.com

Energy Smart Home Plans

www.energysmarthomeplans.com

Building Component:

Insulated Concrete Forms

Application: New single-family

Year Tested: 2012

Climate Zone: Hot-Humid

PERFORMANCE DATA

HERS Index Rating: 51

Projected Annual Savings: $\$ 1034$

Cost of Energy-Efficiency Measure (including labor): $\$ 4,000$

Incremental Annual Mortgage (30-year, 7\% interest): $\$ 280$

Annual Cash Flow: $\$ 754$

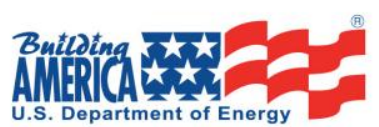

\section{Florida Builder Offers ICF Homes at Low Incremental Cost}

Insulating concrete forms (ICFs) are durable and highly insulating. These qualities are helping them gain wider use in both residential and low-rise commercial building wall applications. R-values ranging from R-20 to R-45 are now available and create a wide range of options for builders, particularly in areas where durable construction with high storm resistance is desirable.

ICFs used for this case study are made up of interlocking units of insulating foam (usually expanded polystyrene). Steel reinforcement bars are fixed in the area between the walls, and concrete is poured into the cavity to create the building's structural envelope. The foam walls are then covered with stone, brick, stucco, or cladding to give the wall a finished appearance and provide an exterior rain barrier. The foam creates a tight air barrier which, accompanied by high insulation levels and structural integrity, produces a complete, highperformance envelope.

The cost for ICF walls typically runs higher than for masonry block or wood framing. A 2001 report by the U.S. Department of Housing and Urban Development estimates that ICF construction generally costs about $5 \%-10 \%$ more than a traditional wood-frame home, or about $\$ 2$ to $\$ 4$ per square foot of floor area. The report also states "First, and foremost, the cost of ICF construction... is very dependent on the familiarity of the contractor and trades people with the product."

For example, Shawn Harvey of Greencastle, Inc. has been working with Building America and its partner, Energy Smart Home Plans,

${ }^{1}$ http://www.huduser.org/Publications/PDF/icfbenefit.pdf 
The picture below shows an approach to ICFs in which rebarreinforced concrete is poured between a sandwich of polystyrene foam. Thickness of both the foam and the concrete can vary to meet varying needs for structural integrity and insulation.
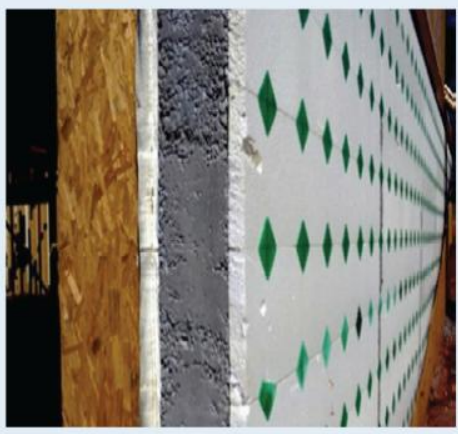

An ICF envelope can be finished with stucco, brick or other materials to produce a desired appearance and add to the aesthetic appeal, as shown below. However, due to the increased wall thickness, the building's footprint is greater than with some other types of framing.

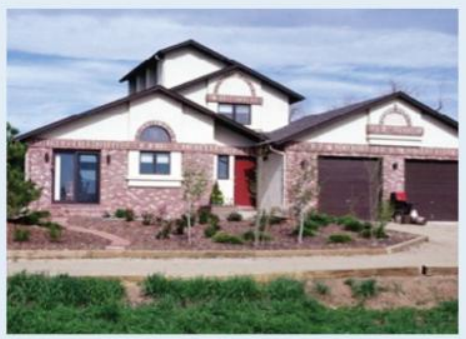

to build ICF homes near Naples, Florida, within $3 \%$ of the price for masonry block housing, which is common in hot humid climates Because building with ICFs is a practiced skill, interested homeowners should work with a builder familiar with ICF construction or builders should seek training in ICF construction practices to keep costs reasonable and to help ensure high quality construction.

\section{Lessons Learned}

- ICF construction takes practice.

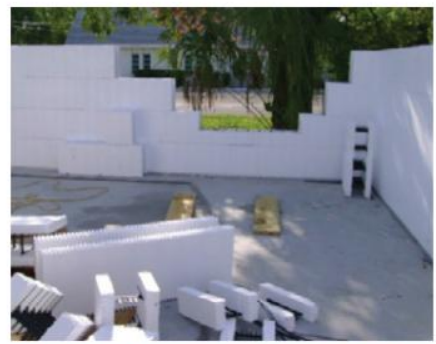

Interlocking pieces are used to create the ICF wall. Concrete is poured onsite into walls of polystyrene foam. Varying thicknesses and materials typically result in $\mathrm{R}$-values between $\mathrm{R}-2 \mathrm{O}$ and R-45. Many times furring strips are used to allow cladding to be easily attached to the exterior.

To ensure a cost effective and high quality installation, homeowners should look for builders who have some experience with ICFs

- In Greencastle's Sandalwood home, the air tightness and high thermal performance of ICF construction help achieve monthly utility bills of about $\$ 64$, or about half of the amount of other new homes in the area.

- Increased R-value for ICF walls will have the most effect on energy efficiency in areas with high heating or cooling demand. In addition, the high thermal mass of ICFs will lead to greater benefits in areas with wide variations in daytime and nighttime temperatures and for homes using passive solar features.

\section{Looking Ahead}

The combined advanatages of structural integrity, low air leakage, and high insulation value make ICF construction an attractive option in many building applications. Insterested builders and homeowners "It works and is cost effective, too!"

Sean Harvey, President should consider cost and the need for contractor experience in their decision making. The U.S. Department of Energy has more information on ICFs at their Energy Savers website, which can be found at http://www.energysavers.gov/. Promotional information is available at the EPS Industry Alliance website at http://www.forms.org/.

\section{Es:TERTY}

Energy Efficiency \& Renewable Energy
For information on Building America visit buildingamerica.gov. The website contains expanded case studies, technical reports, and best practices guides. 


\section{BUILDING TECHNOLOGIES PROGRAM}

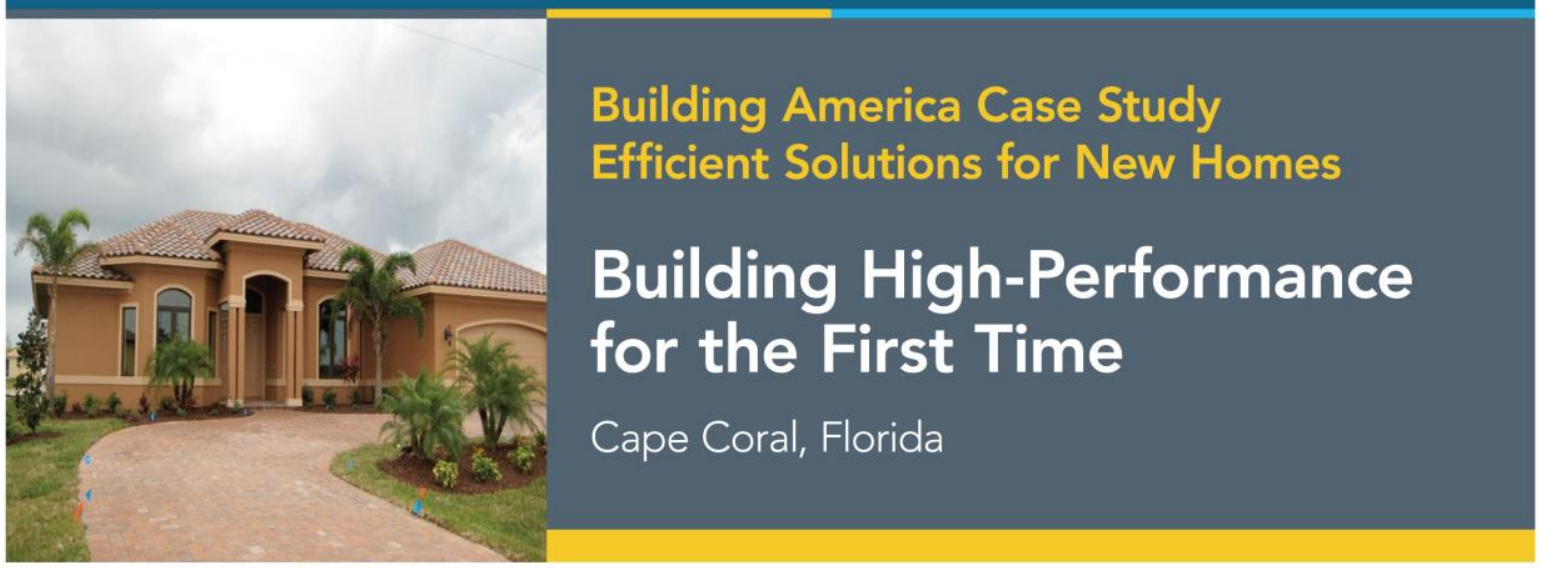

PROJECT INFORMATION

Construction: New

Type: Single-family

Partners:

Pacific Northwest National Laboratory www.pnnl.gov

Energy Smart Home Plans

http://www.energysmarthomeplans.com/

Florida H.E.R.O.

http://www.floridahero.com/

Builder: Ravenwood Homes

Size: $2,248 \mathrm{ft}^{2}$

Date Completed: March 2012

Climate Zone: Hot-Humid

\section{PERFORMANCE DATA}

\begin{tabular}{l|c|c|}
\hline & With PV & Without \\
\cline { 2 - 3 } Cost of measures & $\$ 40,000$ & $\$ 15,000$ \\
\hline $\begin{array}{l}\text { Incremental } \\
\text { annual mortgage }\end{array}$ & $\$ 2,000$ & $\$ 750$ \\
\hline \begin{tabular}{l} 
HERS \\
\hline $\begin{array}{l}\text { Projected annual } \\
\text { savings* }\end{array}$
\end{tabular} & $\$ 1,690$ & $\$ 483$ \\
\hline Annual cash flow & $-\$ 310$ & $-\$ 267$ \\
\hline
\end{tabular}

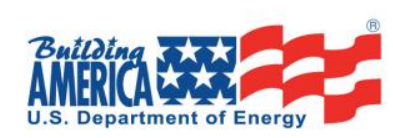

\section{Builder Achieves HERS 15 on First High-Performance Home}

Ravenwood Homes built its first high-performance home in southwestern Florida in 2011. A Building America design team consisting of Pacific Northwest National Laboratory, Energy Smart Home Plans, LLC, and Florida HERO assisted him in designing and building a home that ultimately achieved a HERS of 15 . Not counting the nearly $6 \mathrm{~kW}$ solar Photovoltaic system, the home would achieve a rating of 65 .

A key energy-saving feature of the home is a continuous ceiling designed to separate the vented attic from conditioned space. By building interior walls without double top plates and keeping the tops of the interior framing about $5 / 8$ of an inch below the ceiling joists, ceiling drywall was slid into place over the tops of the interior walls without much cutting and trimming. Drywall above the duct chases was installed first, before the ducts were installed, to air seal the tops of the chases.

This builder's experience demonstrates how important installation details are in avoiding thermal bypasses and maintaining a fully aligned air barrier and thermal barrier. For example, the builder initially used inset stapling to secure kraft-faced insulation in the walls, which creates creases in the face of the insulation that serve as potential pathways for air movement. This problem had to be corrected before drywall was installed. In addition, the builder installed 72 recessed can lights in the home rather than the

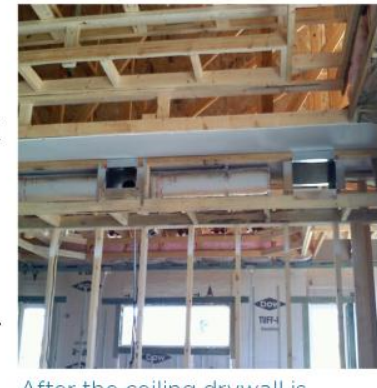

After the ceiling drywall is installed, the ducts can be hung in place and the chase framed around the ductwork for drywall. 


\section{KEY ENERGY-EFFICIENCY MEASURES}

HVAC:

- SEER 16 AC with strip heat (little heating load in south Florida)

- All ductwork in conditioned space

- Positive pressure whole-house ventilation system (run-time only) all exhaust fans vented to outside.

Envelope:

- Concrete block with 1-in. rigid foam insulation applied to the interior of the block wall with furring strips and drywall on top for some exterior walls. 16-in. on-center wood frame with R-19 fiberglass batt insulation on remaining exterior walls

- Vented attic with R-38 fiberglass batt insulation on the attic floor and radiant barrier on the roof deck

- Low-E vinyl windows $(U=0.26-$ $0.55, \mathrm{SHGC}=0.18-0.70$ )

- Moderately tight building envelope, $\mathrm{ACH} 50=4.39$

Lighting, Appliances, and Water Heating:

- $100 \%$ compact fluorescent lighting

- ENERGY STAR ${ }^{\circ}$ appliances

- Solar thermal with $120 \mathrm{gal}$ tank Open Loop Direct System (2) 4-ft $\times 8$-ft panels

- 26-panel PV array, $5.98 \mathrm{~kW}$
12 specified in the design. Although the can lights were sealed to the drywall, this change pushed the originally anticipated building infiltration rate of $2.0 \mathrm{ACH} 50$ (air changes per hour at 50 pascals of pressure) to 4.39 ACH50, or more than twice what had been expected.

This home, as Ravenwood's first, was more expensive than it needed to be and did not have a positive cash flow, despite the good energy performance. As the builder becomes

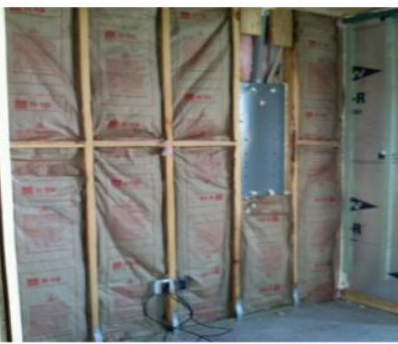

nset stapling was used to fasten insulation to the sides of framing created thermal bypass. The builder restapled the kraft tabs to the stud faces to remedy this problem. more familiar with high-performance building practices and develops relationships with equipment suppliers, costs should come down and result in significant cost and energy savings in future high-performance Ravenwood homes.

\section{Lessons Learned}

- Ducts in conditioned space and the ceiling air barrier were instrumental in achieving moderate air leakage rates and scoring well on the HERS Index, although additional can lights penetrated the ceiling in many locations

- Training was important for the installer to achieve best practices. Involving the builder, designer, and building science consultant in the training of all onsite workers helped to meet efficiency goals

- Design decisions made in the field can dramatically influence energy performance. In addition to the recessed can lights, changes for this house included the addition of a swimming pool pump, downgrading the AC system, and installing a smaller PV array.

"I expected major changes to the building process but building my first high-performance home just required small adjustments in the timing of the trades. This has given new life to my business."

Dave Wishtichin, Head of Construction Ravenwood Homes 


\section{BUILDING TECHNOLOGIES PROGRAM}

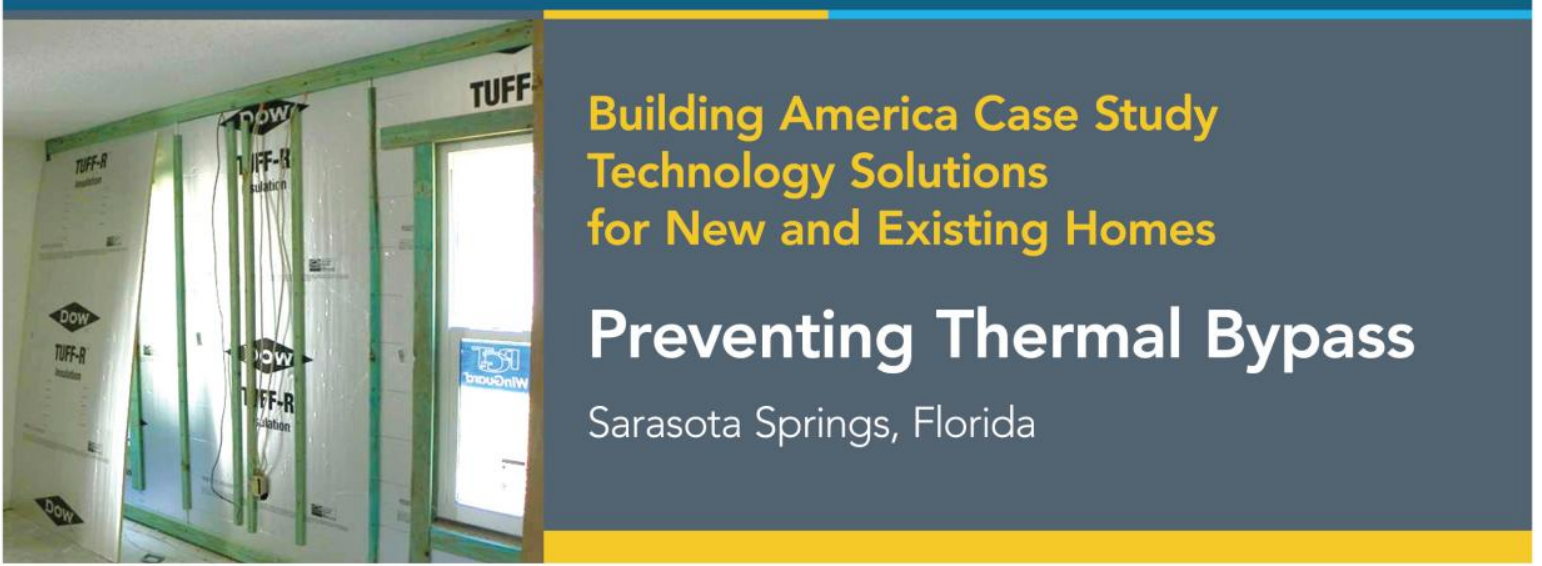

\section{PROJECT INFORMATION}

Location: South Sarasota County, FL Partners:

Pacific Northwest National Laboratory www.pnnl.gov

Energy Smart Home Plans

http://www.energysmarthomeplans.com/

Habitat for Humanity, South Sarasota http://www.habitatsouthsarasota.org/

Building Component: Fully-aligned air and thermal barriers

Application: New, single-family

Size: $1,055 \mathrm{ft}^{2}$

Year Tested: 2012

Climate Zone: Hot-Humid

\section{PERFORMANCE DATA}

Projected Whole House Energy Savings: $34 \%$ based on HERS 66 rating

Projected Whole-House Energy Cost Savings: $\$ 29 /$ month or $\$ 345 /$ year (based on HERS certificate)

\section{Air Sealing and Alignment of Air and Thermal Barriers Required to Prevent Bypass}

Thermal performance requires more than high R-value insulation - continuous air barriers in full alignment with insulation also play an important role in achieving energy performance. Thermal bypasses can increase energy use by allowing air currents to circumvent insulation. ENERGY STAR's Thermal Bypass Inspection Checklist provides a systematic way to close these gaps and must be completed before a home can receive the ENERGY STAR label.

Alignment of air and thermal barriers is among the most important elements of the checklist. Alignment means that insulation must be flush on all sides with structural lumber and gypsum board because any gaps, such as those created by inset stapling or the haphazard placement of insulation, result in potential pathways for convective air currents. Also, if the air barrier is not aligned with the insulation or has leaks in it, air can flow through the insulation, negating the purpose of thermal barrier. Even small gaps in the air barrier, such as seams in foam board or wiring penetrations, need to be sealed to prevent air from flowing through the gaps whenever pressure differences exist between the inside and outside of the home, or between conditioned and nonconditioned spaces, created by wind and temperature differences.

Building America partner Habitat for Humanity in South Sarasota County, Florida, built a single-family home in 2012 on a small budget using donated appliances that were not at ENERGY STAR levels. In addition to the Thermal Bypass Checklist, energy efficiency measures included the installation of a SEER 14 heat pump, R-7.8 rigid insulation in the attic, and 100\% CFL lighting. Despite the budget challenges, the 1,055-square-foot, slab-on-grade home reached 66 on the HERS Index through the combined effect of all of the measures.

Volunteer professional builders attached rigid polyisocyanurate insulation to the interior face of concrete block walls by nailing furring strips to the interior surface of the insulation. Insulation was installed before any interior framing was added to avoid thermal breaks where interior walls intersect the insulation. 


\section{Installing Batt Insulation - The Right and the Wrong Way}

Both insulation methods do a good job of avoiding gaps from ill-fitting pieces.

Right

EPA's Thermal Bypass Checklist requires alignment between the thermal and air barriers. One technique is to staple the insulation to the joist faces as shown in the picture below.

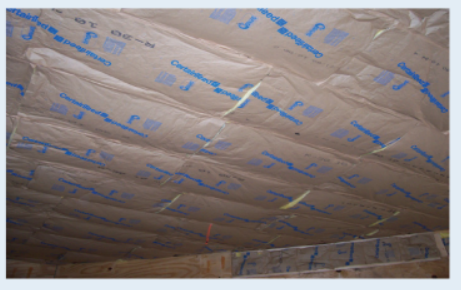

\section{Wrong}

In the picture below, inset stapling of batt insulation to the sides of studs leaves gaps between the thermal barrier (insulation) and the air barrier (drywall). These gaps create cold spots on walls and pathways for air currents that pull air through leaks in air barriers.

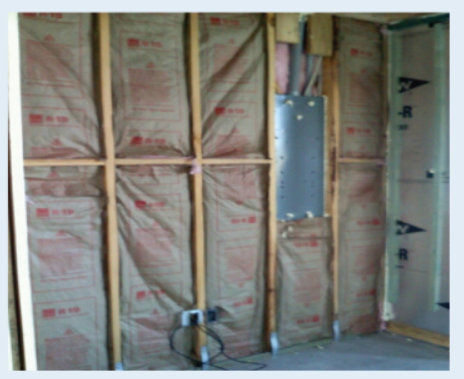

In many cases a properly installed thermal barrier can be compromised by holes or gaps in the air barrier. One approach to ensure the integrity of the air and thermal barrier is to delegate responsibility to one person to verify that air sealing is complete. While some builders may require electrical and plumbing teams to fill their own holes, this project found it effective to have one person follow these teams and ensure that all holes were properly sealed.

\section{Lessons Learned}

- Using low-cost measures, Habitat for Humanity achieved a HERS of 66. If ENERGY STAR appliances could have been used, the rating would have been even better.

- After on-site training for best practice procedures for air sealing and face stapling of batt insulation, professional installers readily picked up these methods.

- Assigning one person on a job site to verify that air sealing was completed ensured the integrity of the thermal and air barrier and achieved energy savings by preventing thermal bypasses.

- Fully-aligned air and thermal barriers help maximize the energy efficiency of the building envelope and minimize utility bills, which is especially important for Habitat's low-income clients. The U.S. EPA estimates that air sealing and fully aligned air barriers can save $15 \%$ on heating and cooling costs. ${ }^{1}$ These increases in energy efficiency are achieved for $\$ 0$ additional material costs and minimal additional labor.

\section{Looking Ahead}

As the number of ENERGY STAR

homes increases, the program's Thermal Bypass Checklist will become more prominent. According to the Building Energy Codes Program at Pacific Northwest National Laboratory, Florida energy codes approximate the 2009 International Energy

Conservation Code, which requires that builders meet an extensive air

"It's great to build affordable homes. But more importantly, our homes must be affordable to operate."

\section{Michael Sollitto Construction Manager Habitat for Humanity South Sarasota Springs} sealing checklist. The 2012 IECC will require that builders meet stringent air sealing as verified with blower door testing. A complete and fully aligned air barrier will be an imporant part of meeting the new IECC performancebased air leakage requirements.

\footnotetext{
U.S. Environmental Protection Agency. "ENERGY STAR Qualified Homes, Version 3 Savings \& Cost Estimate Summary." Available at: http://www.energystar.gov/ia/partners/bldrs_lenders_raters/downloads/EstimatedCostandSavings.pdf
}

\section{Es:TERT}

Energy Efficiency \& Renewable Energy
For information on Building America visit buildingamerica.gov. The website contains expanded case studies, technical reports, and best practices guides. 


\section{BUILDING TECHNOLOGIES PROGRAM}

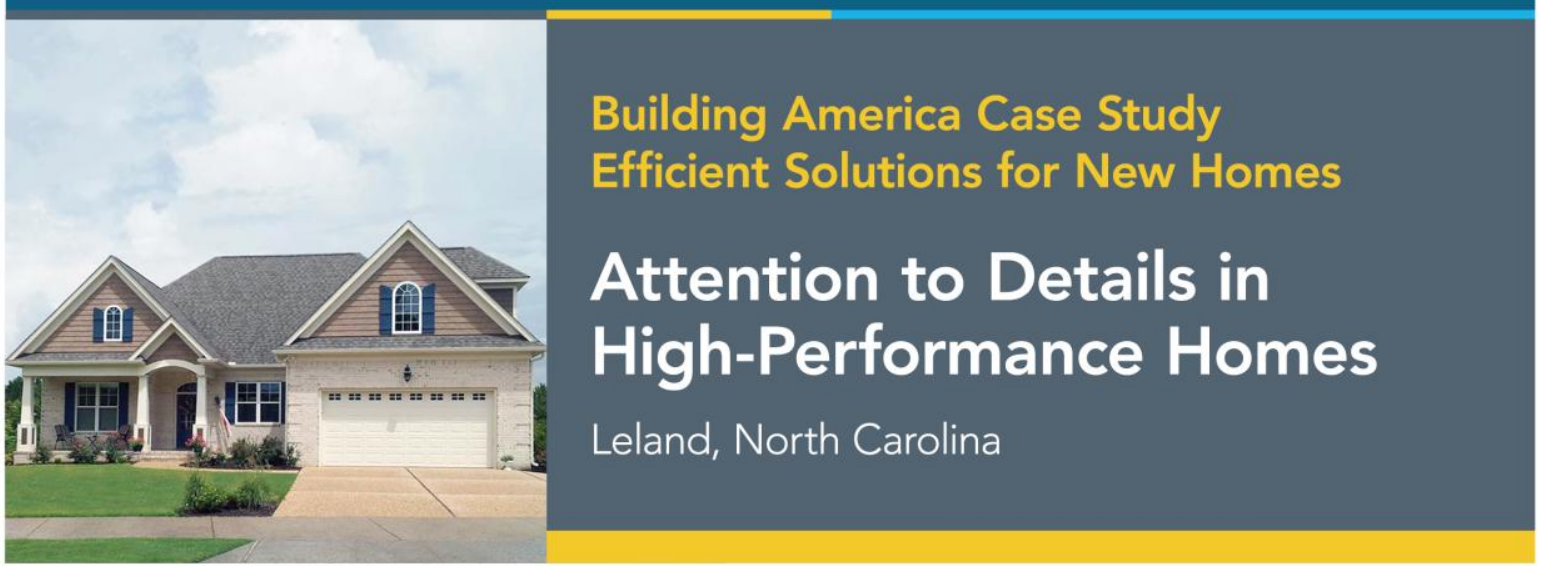

\section{PROJECT INFORMATION}

Construction: New

Type: Single-family

Partners:

Pacific Northwest National Laboratory www.pnnl.gov

Energy Smart Home Plans

http://www.energysmarthomeplans.com/

Florida H.E.R.O.

http://www.floridahero.com/

Builder: Heritage Buildings, Inc.

Size: $2,396 \mathrm{ft}^{2}$

Date Completed: 2011

Climate Zone: Hot-Humid

\section{PERFORMANCE DATA}

Projected annual energy cost:

Heritage Home: $\$ 1,465$ 2009 IECC: $\$ 2,308$

Incremental cost of energy-efficiency measures: $\$ 5,000$

Incremental annual mortgage (30-year, 7\% interest): $\$ 350$

Annual cash flow: $\$ 396$

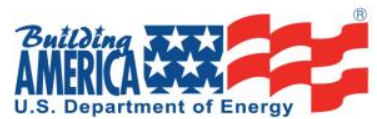

\section{North Carolina Builder Gets Serious About High-Performance}

Building America partners Pacific Northwest National Laboratory, Energy Smart Home Plans and Florida H.E.R.O. recently worked with North Carolina-based builder Heritage Buildings, Inc., to make the conversion to high-performance building in the hot-humid regions of the Atlantic seaboard. Searching for new marketing opportunities, Heritage purchased a home plan from ESHP and built a home achieving 56 on the HERS Index with only minor additional costs, despite having little on-site technical assistance.

The result was so successful that Heritage now offers high-performance upgrades to its clients on a regular basis, for $\$ 5,000$ per home. These additional energy efficiency measures will also result in significant savings on energy costs. For example, compared to a neighboring home that is representative of a home built to the 2009 International Energy Conservation Code (IECC), which North Carolina recently adopted as a basis for its state residential energy code, the Heritage home is projected to save $\$ 843$ annually in energy bills. A North Carolina

\begin{tabular}{|l|c|c|}
\hline & Heritage & Neighbor \\
\hline HERS & 56 & 86 \\
\hline Size $\left[\mathrm{ft}^{2}\right.$ ] & 2,396 & 2,780 \\
\hline Building Leakage [ACH50] & 3.41 & 5.38 \\
\hline Duct leakage [CFM25 out] & 46 & 157 \\
\hline Heat pump & 16 SEER/9 HSPF & 13 SEER/7.7 HSPF \\
\hline Water heater & Tankless propane (0.82 EF) & 50 gallon electric (0.9 EF) \\
\hline Attic insulation & R-38 w/ radiant barrier & R-30 \\
\hline Wall insulation & R-15 & R-13 \\
\hline Ventilation & Balanced & None \\
\hline Windows & Low-E 0.32/0.33 & Low-E 0.35/0.35 \\
\hline
\end{tabular}




\section{High-Performance Appearance:}

\section{Fact or Fiction?}

Below are pictures of neighboring homes. The upper has standard features (HERS 86), the home in bottom photo has highperformance options (HERS 56).
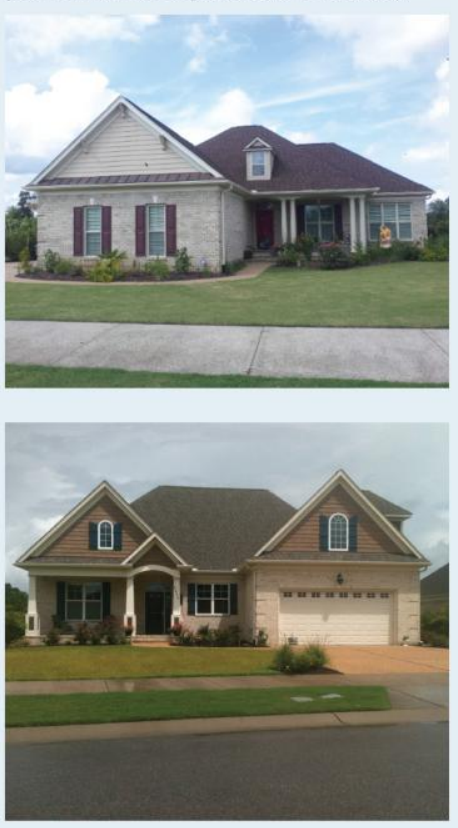

In addition to being energy efficient, high performance homes are more durable and comfortable than conventional homes. Customer satisfaction is important for generating sales leads and understanding the cost of home ownership is important to sales.

code-built home typically results in homes achieving HERS Index levels around 85 .

Many of the high-performance improvements did not come with significant additional costs, but did require more attention to detail. For example, following ENERGY STAR's Thermal Bypass Checklist. To make sure air sealing details were not overlooked in the field, Heritage builder Vic Sikka routinely returned to the construction site to personally seal any holes created by electrical and plumbing installations.

Marketing high-performance homes involves helping buyers understand the value of energy efficiency. Heritage Buildings found that understanding the total cost of home ownership was important to selling the value of high-performance improvements.

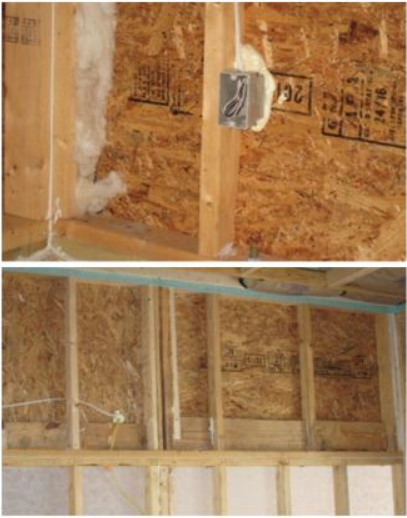

Many high performance improvements require attention to detail rather than a large investment. Electrical and plumbing holes were carefully sealed. Sill plate gasketing was used to seal sheetrock to the top plate. This is one of many low-cost improvements listed on the ENERGY STAR Thermal Bypass Checklist.

\section{Lessons Learned}

- Low utility bills and great customer satisfaction can help builders differentiate their product in the market.

- This builder found that following the EPA Thermal Bypass Checklist was a low-cost way of improving the thermal envelope and reducing energy costs.

- Attention to details, such as filling holes left by electrical teams, is key to any highperformance effort. This, along with other high perfomance measures, will save homeowners in a high performance Heritage home \$396 a year over a 30-year mortgage.
"The builder's commitment to improving their product is seen in the results they achieve."

Vic Sikka, President Heritage Buildings, Inc. 
Appendix C

Energy Smart Home Plans DOE Challenge Home Plan Set 



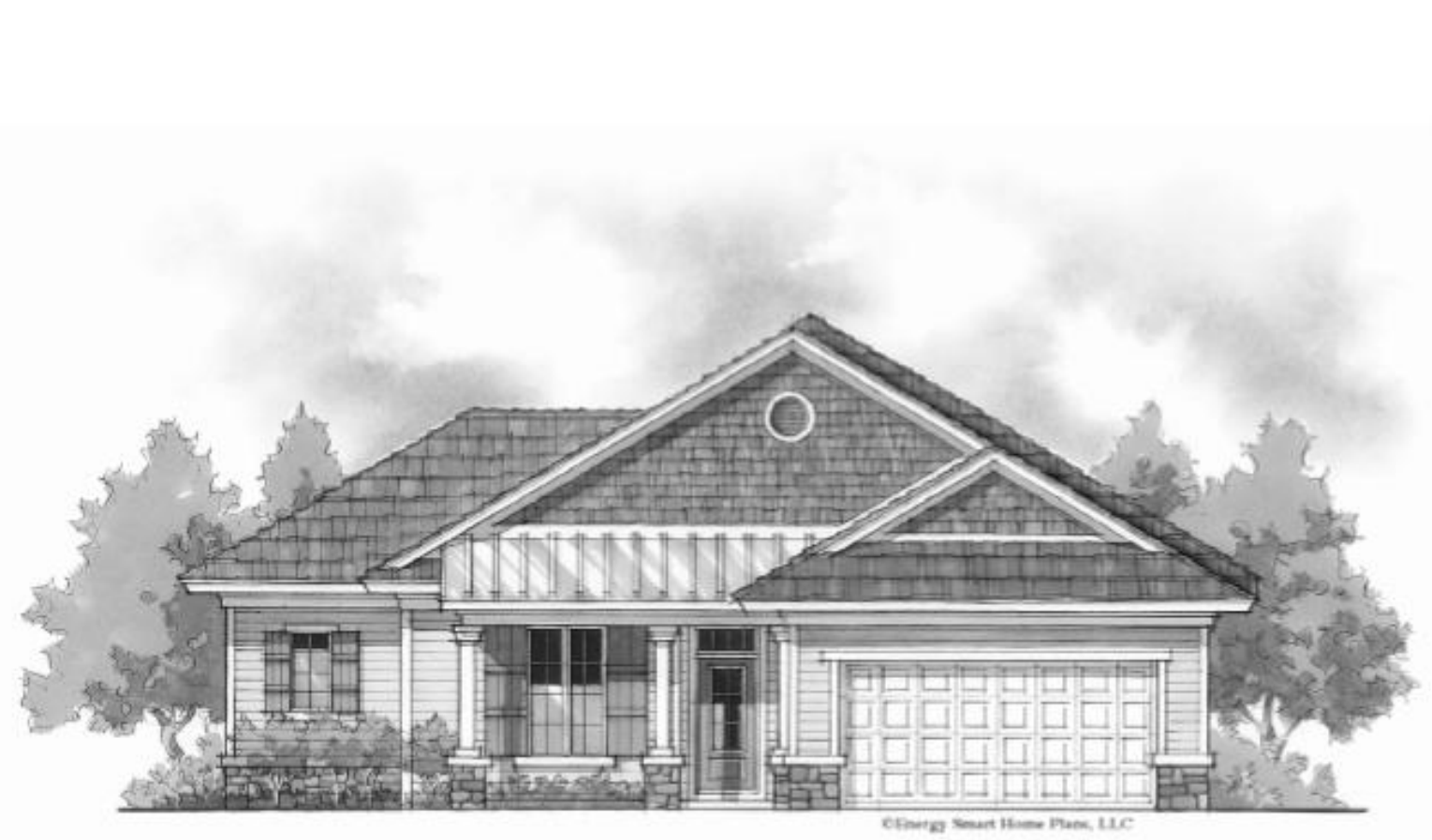

\begin{tabular}{|c|l|}
\hline \multicolumn{2}{|c|}{$\begin{array}{c}\text { ENERGY SMART HOME PLANS } \\
\text { NZR-109-SUMMERVILLE - }\end{array}$} \\
\hline \multicolumn{2}{|c|}{ SHEET INDEX } \\
\hline A-1 & WALL SECTIONS \& DETAILS \\
\hline A-2 & FOUNDATION \& ROOF PLAN \\
\hline A-3 & ELEVATIONS \\
\hline A-4 & SECTIONS \& INT. ELEVATIONS \\
\hline A-5 & REFLECTED CEILING \& ROOF PLANS \\
\hline A-6 & ELECTRICAL PLAN \\
\hline
\end{tabular}

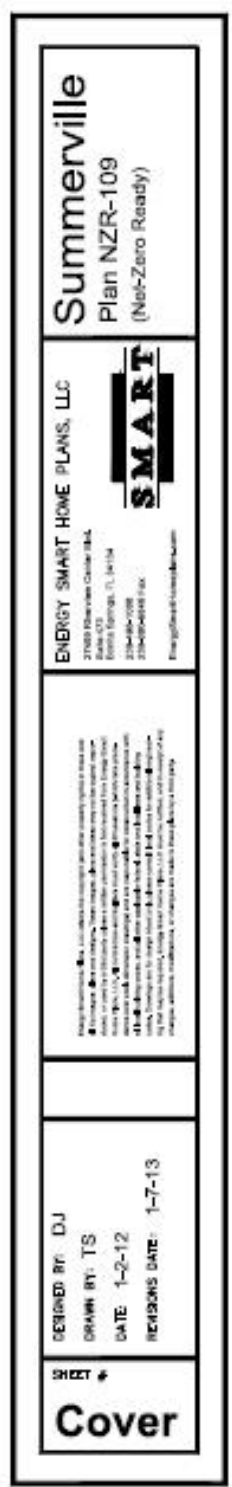



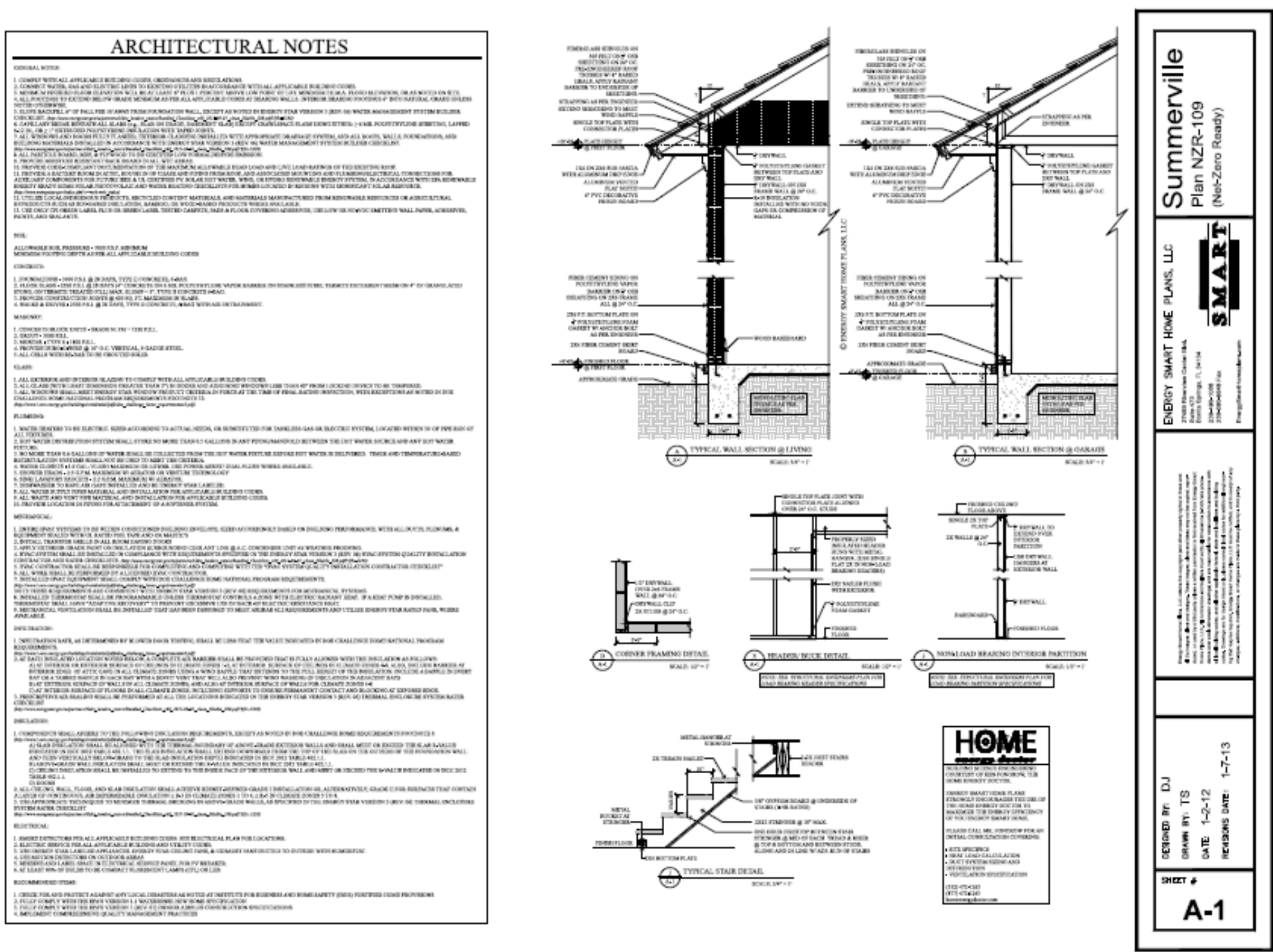

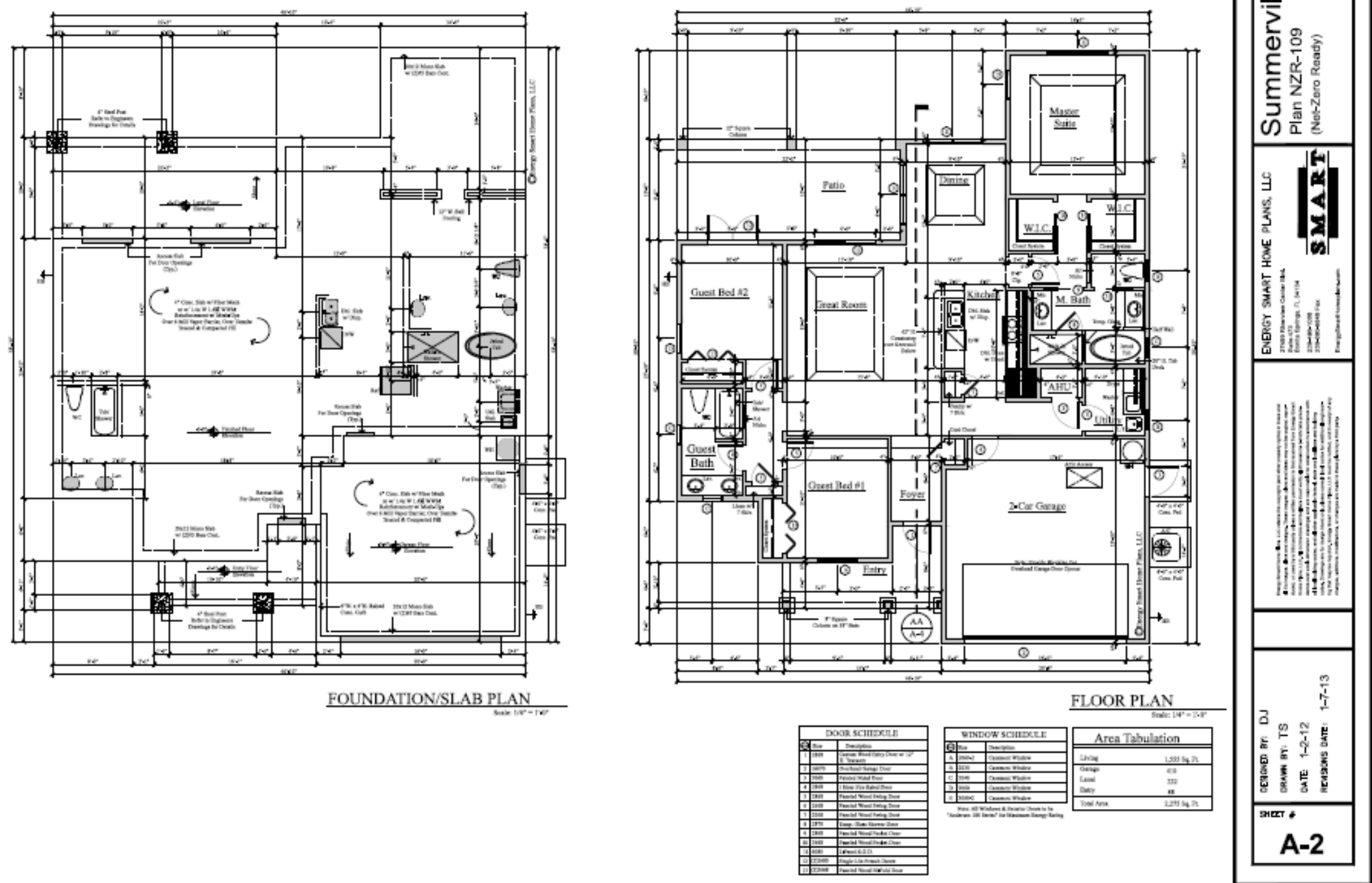


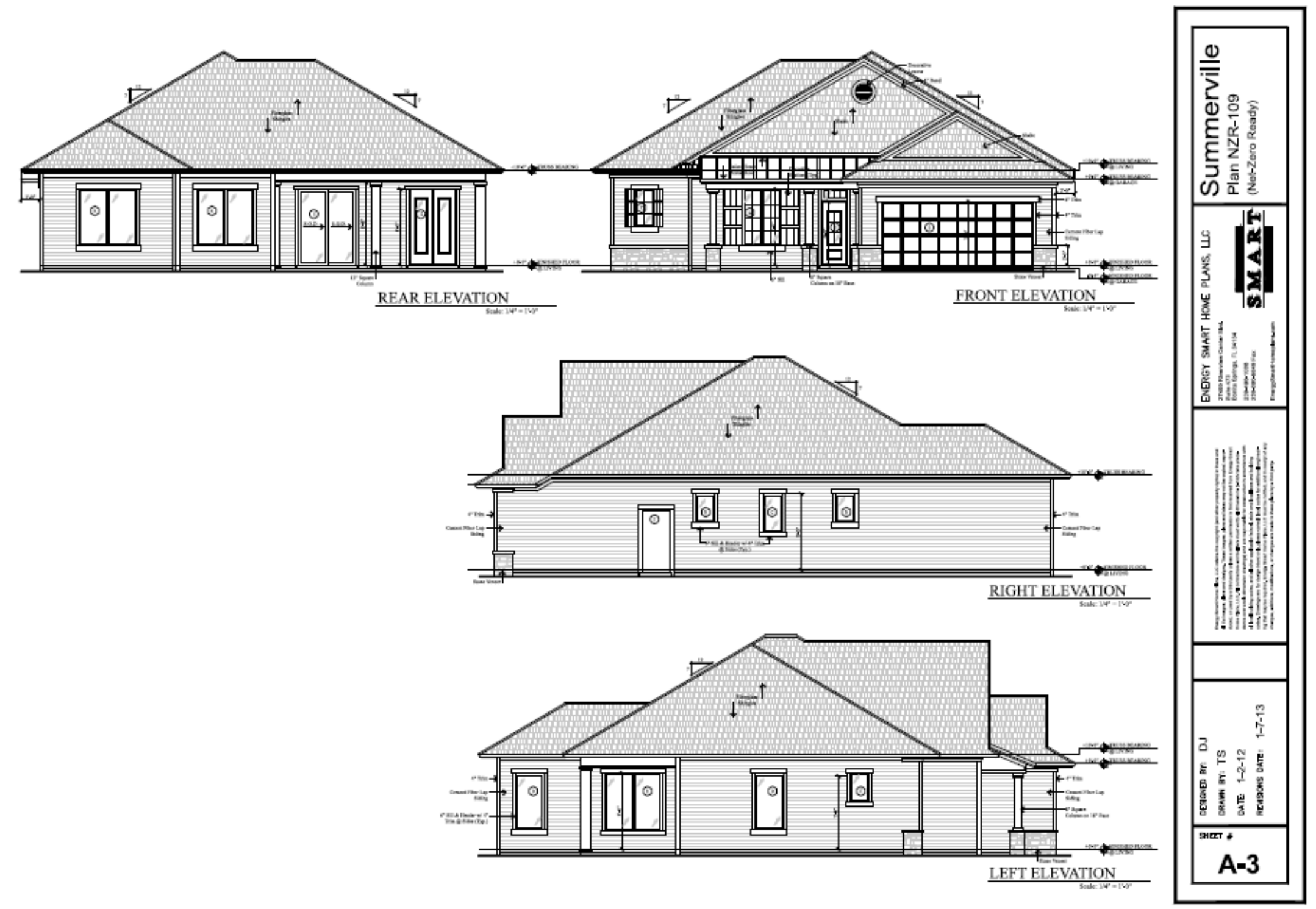




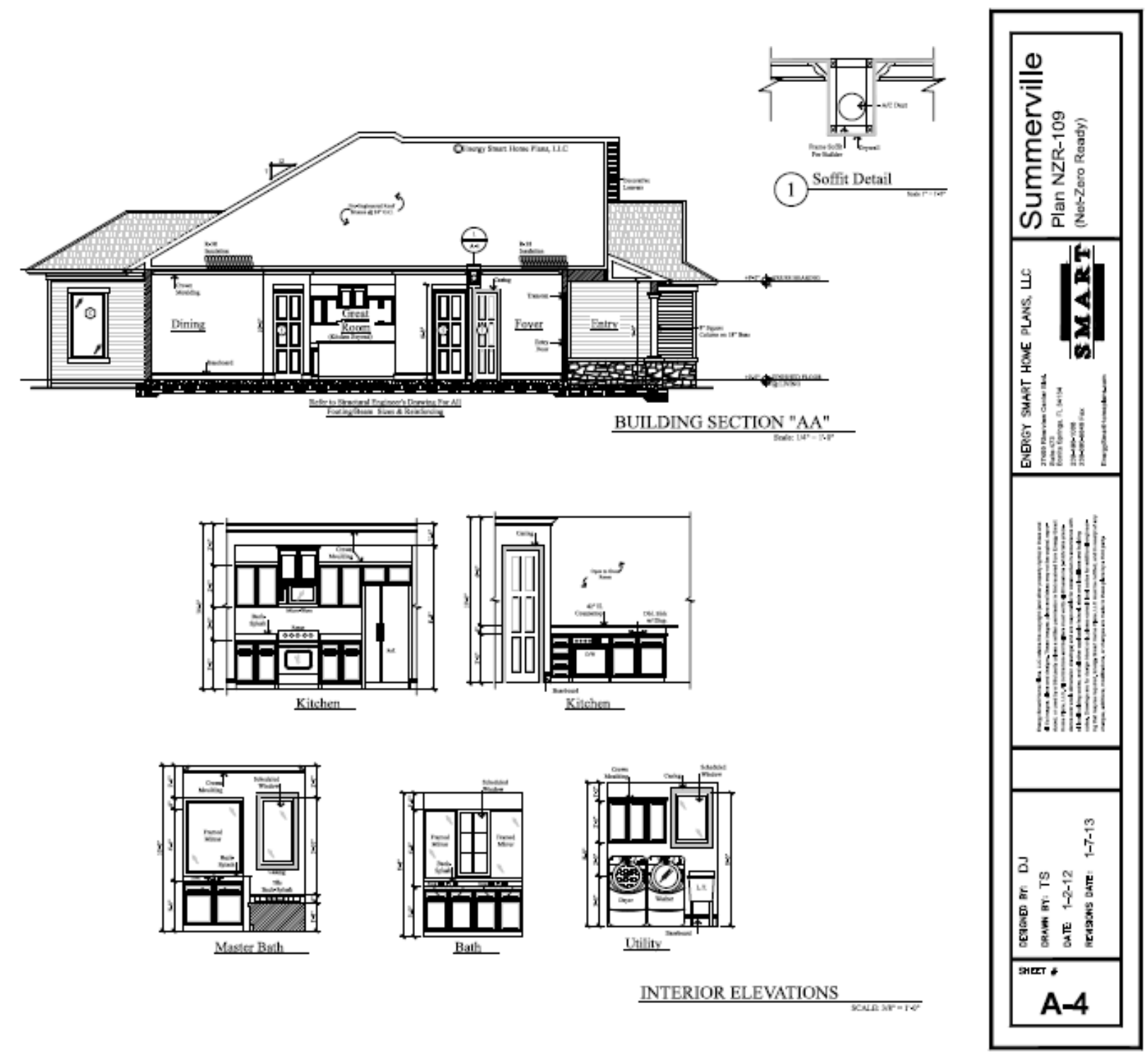




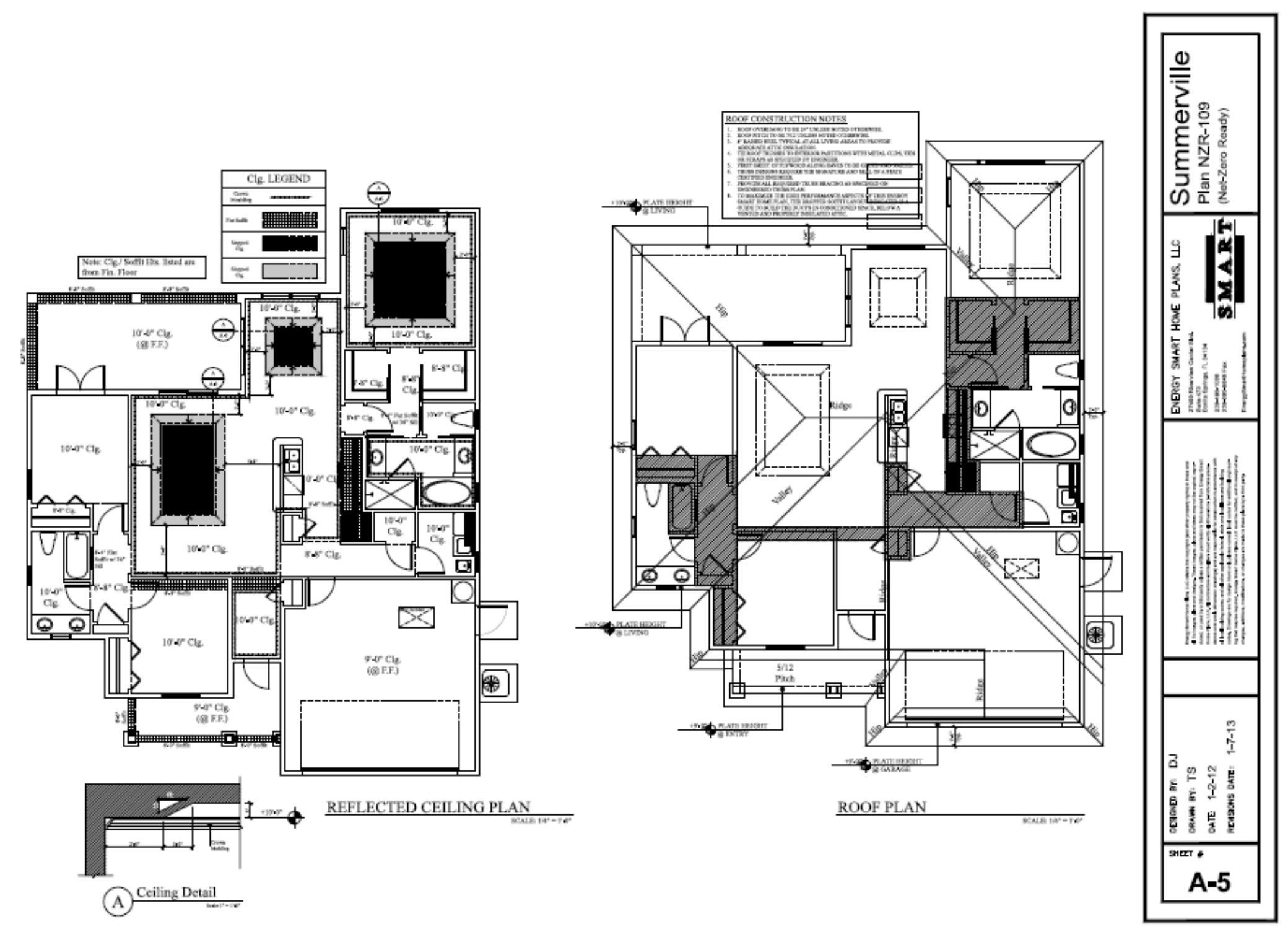




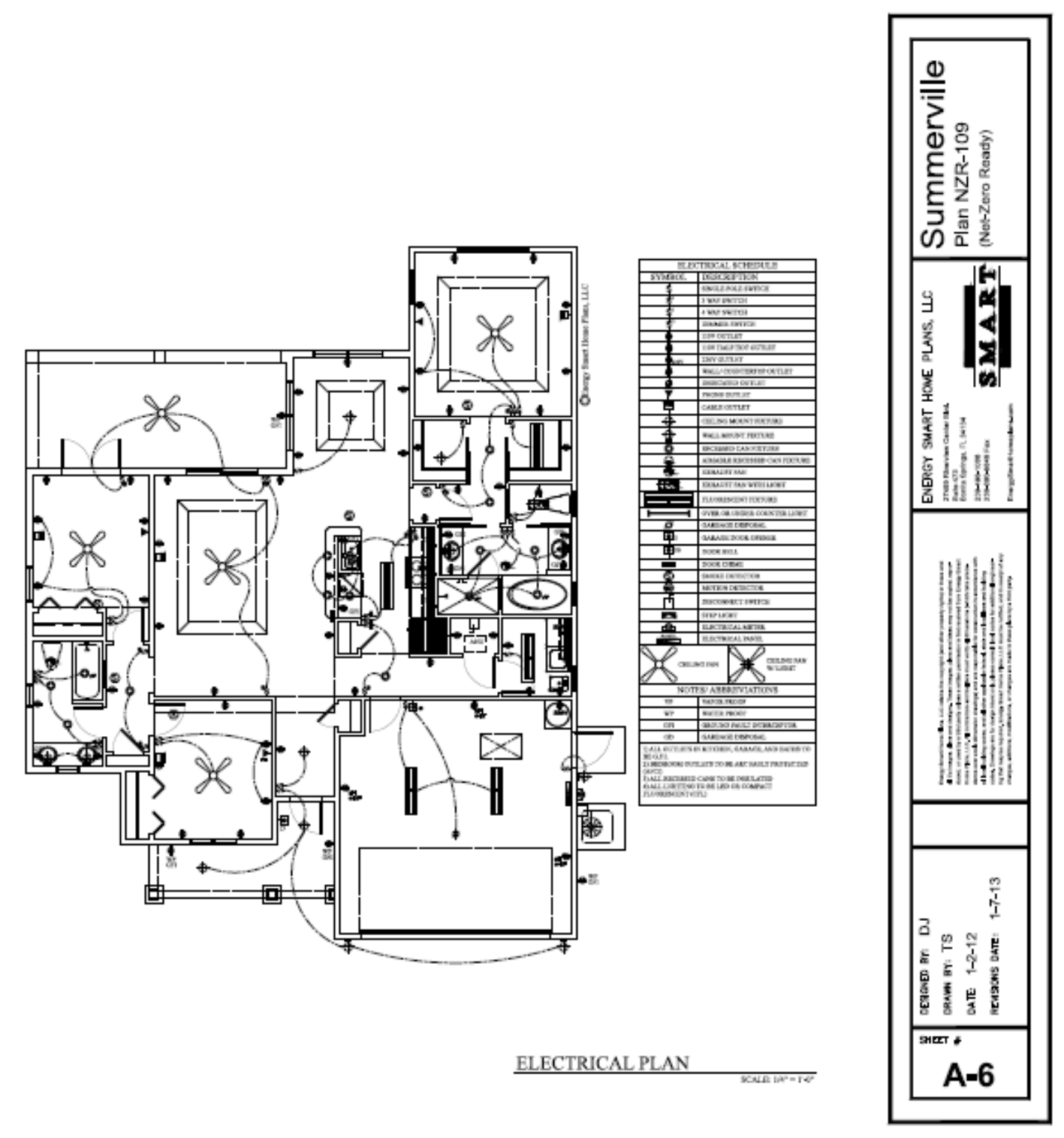





\section{Distribution}

No. of

Copies

U.S. Department of Energy

1000 Independence Ave. SW

Washington, D.C. 20585

Eric Werling

Sam Rashkin

Ken Fonorow

Florida HERO

15220 N.W. $5^{\text {th }}$ Ave.

Newberry, FL 32669

Dave Jenkins

Energy Smart Home Plans

27499 Riverview Center Blvd, Ste. 473

Bonita Springs, FL 34134

Dennis Stroer

Calcs-Plus

121 Triple Diamond Blvd

North Venice, FL 34275
No. of

Copies

\section{Local Distribution}

Pacific Northwest National Laboratory

Michael Baechler

(PDF)

Sarah Widder

(PDF)

Angela Kora 




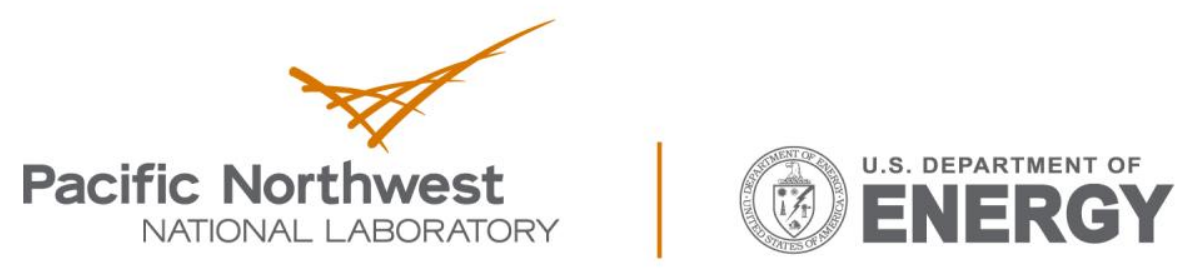

Proudly Operated by Battelle Since 1965

902 Battelle Boulevard

P.O. Box 999

Richland, WA 99352

1-888-375-PNNL (7665)

www.pnnl.gov 